\title{
A U.S. CLIVAR Project to Assess and Compare the Responses of Global Climate Models to Drought-Related SST Forcing Patterns: Overview and Results
}

\author{
Siegfried Schubert, ${ }^{\mathrm{a}}$ DAVid GutZler, ${ }^{\mathrm{b}}$ Hailan WAng, ${ }^{\mathrm{a}, \mathrm{c}}$ Aiguo Dai, ${ }^{\mathrm{d}}$ TOM Delworth, \\ Clara Deser, ${ }^{\mathrm{d}}$ Kirsten Findell, ${ }^{\mathrm{e}}$ Rong Fu, ${ }^{\mathrm{f}}$ Wayne Higgins,, $\mathrm{g}$ Martin Hoerling, \\ Ben Kirtman, ${ }^{\mathrm{i}}$ RANDAl Koster, ${ }^{\mathrm{a}}$ Arun Kumar,g David Legler, ${ }^{\mathrm{j}}$ Dennis LetTenmaier, ${ }^{\mathrm{k}}$

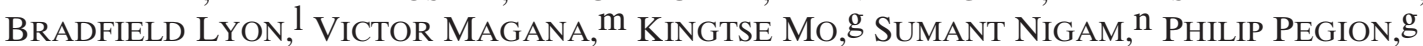 \\ Adam Phillips, ${ }^{\mathrm{d}}$ Roger Pulwarty ${ }^{\mathrm{o}}$ David Rind, $\mathrm{p}$ Alfredo Ruiz-Barradas, ${ }^{\mathrm{n}}$ Jae Schemm,g \\ Richard SeAger,, $\mathrm{q}$ Ronald Stewart ${ }^{\mathrm{r}}$ Max SuArez, ${ }^{\mathrm{a}}$ Jozef Syktus, ${ }^{\mathrm{s}}$ Mingfang Ting, $\mathrm{q}$ \\ ChunZai WANG, ${ }^{\mathrm{t}}$ SCOTT WeAVER, ${ }^{\mathrm{a}, \mathrm{c}}$ AND Ning ZENG ${ }^{\mathrm{n}}$ \\ a Global Modeling and Assimilation Office, Science and Exploration Directorate, NASA GSFC, Greenbelt, Maryland \\ $\mathrm{b}$ Department of Earth and Planetary Sciences, University of New Mexico, Albuquerque, New Mexico \\ c Goddard Earth Sciences and Technology Center, University of Maryland, Baltimore County, Baltimore, Maryland \\ $\mathrm{d}$ National Center for Atmospheric Research, Boulder, Colorado \\ e National Oceanic and Atmospheric Administration/Geophysical Fluid Dynamics Laboratory, Princeton University, Princeton, \\ New Jersey \\ f Jackson School of Geosciences, The University of Texas at Austin, Austin, Texas \\ $\mathrm{g}$ NOAA/NWS/NCEP/Climate Prediction Center, Washington, D.C. \\ h NOAA/Earth System Research Laboratory, Boulder, Colorado \\ i Rosenstiel School of Marine and Atmospheric Science, University of Miami, Miami, Florida \\ j U.S. Climate Variability and Predictability Research Program, Washington, D.C. \\ $\mathrm{k}$ Department of Civil and Environmental Engineering, University of Washington, Seattle, Washington \\ ${ }^{1}$ International Research Institute for Climate and Society, Lamont-Doherty Earth Observatory, Columbia University, Palisades, New York \\ $\mathrm{m}$ Center for Atmospheric Sciences, National Autonomous University of Mexico, Mexico City, Mexico \\ n Department of Atmospheric and Oceanic Science, University of Maryland, College Park, College Park, Maryland \\ o NOAA/National Integrated Drought Information System, Boulder, Colorado \\ p NASA Goddard Institute for Space Studies, New York, New York \\ q Lamont-Doherty Earth Observatory, Columbia University, Palisades, New York \\ ${ }^{\mathrm{r}}$ Department of Environment and Geography, University of Manitoba, Winnipeg, Manitoba, Canada \\ s Environmental Protection Agency, Indooroopilly, Queensland, Australia \\ ${ }^{\mathrm{t}}$ NOAA/Atlantic Oceanographic and Meteorological Laboratory/Physical Oceanography Division, Miami, Florida
}

(Manuscript received 29 January 2009, in final form 24 April 2009)

\begin{abstract}
The U.S. Climate Variability and Predictability (CLIVAR) working group on drought recently initiated a series of global climate model simulations forced with idealized SST anomaly patterns, designed to address a number of uncertainties regarding the impact of SST forcing and the role of land-atmosphere feedbacks on regional drought. The runs were carried out with five different atmospheric general circulation models (AGCMs) and one coupled atmosphere-ocean model in which the model was continuously nudged to the imposed SST forcing. This paper provides an overview of the experiments and some initial results focusing on the responses to the leading patterns of annual mean SST variability consisting of a Pacific El Niño-Southern Oscillation (ENSO)-like pattern, a pattern that resembles the Atlantic multidecadal oscillation (AMO), and a global trend pattern.

One of the key findings is that all of the AGCMs produce broadly similar (though different in detail) precipitation responses to the Pacific forcing pattern, with a cold Pacific leading to reduced precipitation and a warm Pacific leading to enhanced precipitation over most of the United States. While the response to the Atlantic pattern is less robust, there is general agreement among the models that the largest precipitation
\end{abstract}

Corresponding author address: Siegfried D. Schubert, Global Modeling and Assimilation Office, NASA GSFC, Greenbelt, MD 20771. E-mail: siegfried.d.schubert@nasa.gov 
response over the United States tends to occur when the two oceans have anomalies of opposite signs. Further highlights of the response over the United States to the Pacific forcing include precipitation signal-to-noise ratios that peak in spring, and surface temperature signal-to-noise ratios that are both lower and show less agreement among the models than those found for the precipitation response. The response to the positive SST trend forcing pattern is an overall surface warming over the world's land areas, with substantial regional variations that are in part reproduced in runs forced with a globally uniform SST trend forcing. The precipitation response to the trend forcing is weak in all of the models.

It is hoped that these early results, as well as those reported in the other contributions to this special issue on drought, will serve to stimulate further analysis of these simulations, as well as suggest new research on the physical mechanisms contributing to hydroclimatic variability and change throughout the world.

\section{Introduction}

In recognition of the profound societal impact of drought in many regions of the world and the emerging capabilities in simulating drought with global climate models, the U.S. Climate Variability and Predictability (CLIVAR) program initiated a drought working group in 2006 to "facilitate progress on the understanding and prediction of long-term (multi-year) drought over North America and other drought-prone regions of the world, including an assessment of the impact of global change on drought processes" (Gutzler and Schubert 2007). The specific tasks of the working group were to 1) propose a working definition of drought and related model predictands of drought, 2) coordinate evaluations of existing relevant model simulations, 3) suggest new experiments (coupled and uncoupled) designed to address outstanding uncertainties in the nature of drought, 4) coordinate and encourage the analysis of observational datasets to reveal antecedent linkages of multiyear droughts, and 5) organize a community workshop to present and discuss the results.

This paper provides an overview and some results of task 3 of the working group, involving the design, coordination, implementation, and initial evaluation of a new set of model simulations that address the roles of sea surface temperature forcing and land-atmosphere feedbacks in the development and maintenance of drought. This work extends and builds upon recent modeling studies (e.g., Hoerling and Kumar 2003; Schubert et al. 2004a,b; Wang et al. 2008, 2009) as well as numerous observationally based studies (e.g., Trenberth and Guillemot 1996; Mo et al. 1997; Ting and Wang 1997; Nigam et al. 1999; Koster et al. 2003; Ruiz-Barradas and Nigam 2004; McCabe et al. 2004; Wang et al. 2006) that have provided substantial insights into the nature of drought and the important role of both the oceans and land-atmosphere interactions. In particular, this work addresses the remaining uncertainties regarding the nature of the physical mechanisms linking remote SST forcing to regional drought, the relative contributions of the different ocean basins and different time scales of SST variability, and the strength of land- atmosphere feedbacks, and thereby starts to frame fundamental questions about the predictability of longterm drought. Specific questions addressed by the working group include the following: What are mechanisms that maintain drought across the seasonal cycle and from one year to the next? What is the role of the different ocean basins, including the impact of El Niño-Southern Oscillation (ENSO), the Pacific decadal oscillation (PDO), the Atlantic multidecadal oscillation (AMO), and warming trends in the global oceans? What is the role of the land? To what extent can droughts develop independently of oceanic variability resulting from year-to-year memory that may be inherent to the land?

To address these questions, the working group proposed that a number of mechanistic experiments be performed that are designed to address some of the key issues outlined above using several different global climate models. A key objective was to be able to assess the model dependence of the results unambiguously. To accomplish that, it was proposed that each model be forced with the same set of idealized SST forcing anomalies. In addition, it was proposed that a control run be produced in which each model was forced with the same climatological SSTs. To allow an assessment of land-atmosphere feedbacks, an additional set of runs was proposed in which the soil moisture was fixed using a common approach that could be easily implemented in each of the models. The main SST forcing patterns, the experiments, and the models are described in section 2 . Section 3 presents some basic comparisons of the model responses to the leading patterns of SST variability, with a focus on the United States. The summary and conclusions are given in section 4. Information on auxiliary experiments and data availability are given in the appendix.

\section{The SST forcing patterns, experiments, and models}

\section{a. SST forcing patterns}

The basic SST data used in this study are the 19012004 monthly SST data produced by Rayner et al. (2003). The leading patterns of SST variability are isolated using 


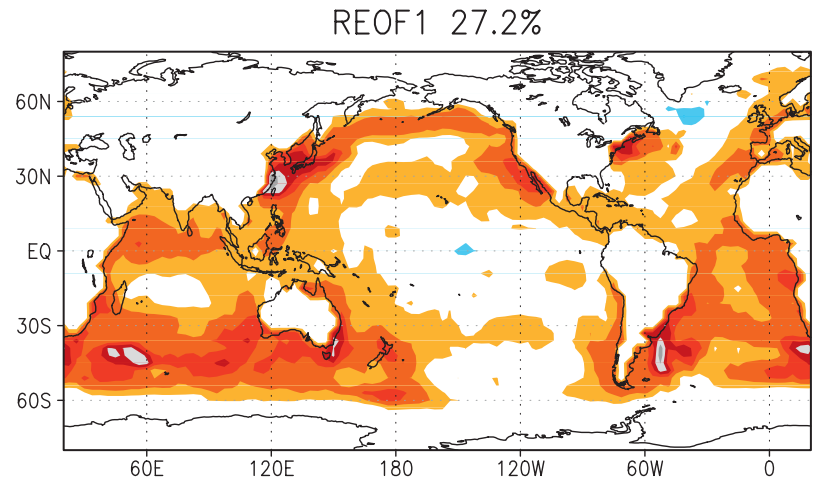

REOF2 $20.5 \%$

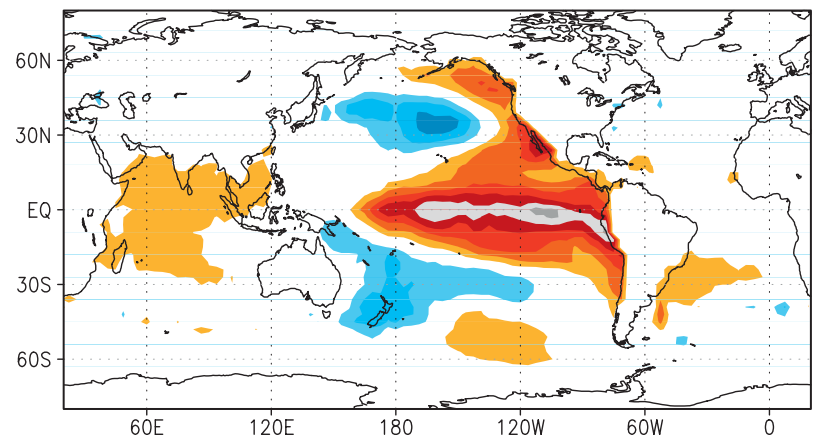

REOF3 $5.8 \%$

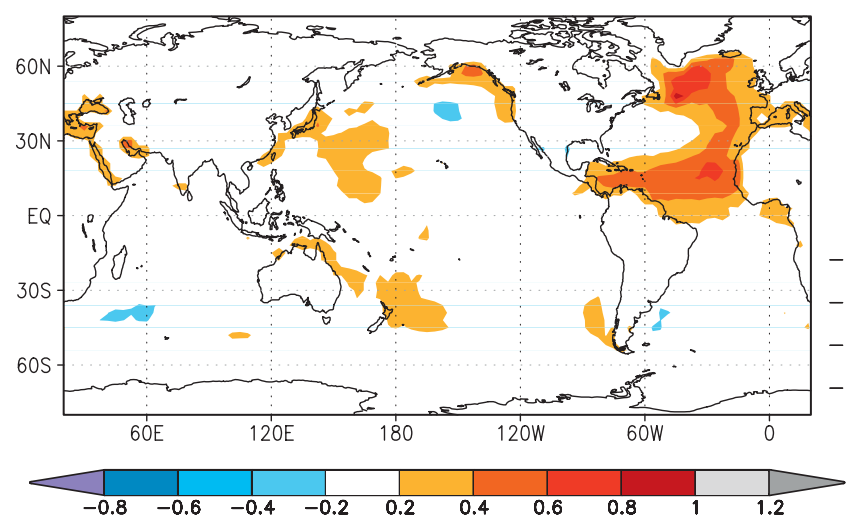

PC1

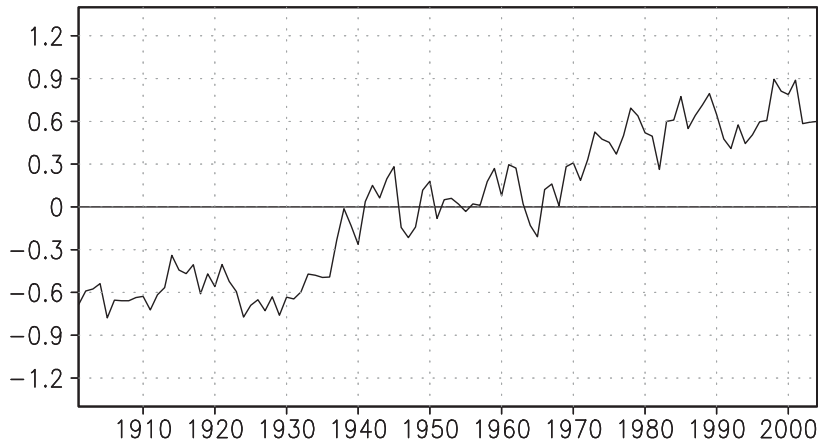

PC2

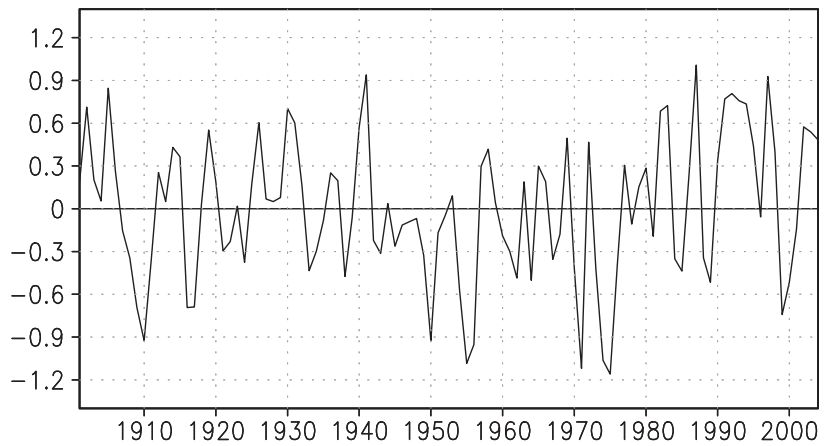

FIG. 1. The (left) three leading rotated EOFS and (right) associated PCs of the annual mean SST based on the period of 1901-2004. The values are scaled so that the product of the PCs and EOFs gives units of degrees Celsius. The Pacific and Atlantic patterns reflect the two standard deviation forcing amplitudes applied to the models, while the trend pattern must be divided by a factor of 2 to obtain the forcing amplitude.

rotated empirical orthogonal functions (REOFs), where varimax rotation (e.g., Richman 1986) is used to help separate the leading patterns of Pacific and Atlantic SST variability.

The REOFs are computed from global gridded values of annual mean SST for the period of 1901-2004. The use of annual means is meant to address the basic question of the nature of the forcing of regional hydroclimates on interannual time scales. This, of course, does not distinguish between, for example, ENSO and Pacific decadal variability (e.g., Barlow et al. 2001); the responses to leading SST anomaly patterns that occur on these different time scales is addressed with other supplementary REOFs described in the appendix. 
Figure 1 shows the three leading REOFs and associated principal components (PCs) of the annual mean SST. The first is a global trend pattern, with warming occurring over most of the global ocean. In fact, this spatial pattern can essentially be reproduced by plotting the slopes of the linear trends fit to the 1901-2004 annual mean SST at each grid point (not shown). The associated PC shows a somewhat more complicated (nonlinear) long-term time evolution, showing an almost step-like increase at about 1940, and a clear trend occurring only after the mid-1960s ${ }^{1}$. The second REOF is a pan-Pacific ENSO-like pattern that includes a weak Indian Ocean component. The associated PC shows that this pattern varies on both interannual (ENSO) and decadal time scales, with the latter including the well-known shift that occurred in the mid-1970s (e.g., Trenberth and Hurrell 1994). The third REOF is confined for the most part to the North Atlantic Ocean and resembles the Atlantic multidecadal oscillation pattern (Enfield et al. 2001). The associated PC shows that while this pattern has clear decadal variability, it also exhibits considerable interannual variations. These three leading rotated EOFs will in the following be referred to as the trend, Pacific, and Atlantic forcing patterns.

\section{b. Proposed experiments}

The proposed experiments consist of $50-\mathrm{yr}^{2}$ simulations in which the model is forced with one or more of the idealized SST anomaly patterns (the trend, Pacific, and Atlantic forcing patterns described above ${ }^{3}$ ). The full forcing patterns are produced by adding scaled versions of the REOFs to the long-term monthly varying SST climatology (defined for the period of 1901-2004). The scaling factor for the Pacific and Atlantic consists of \pm 2 standard deviations of the associated PCs. This rather large amplitude was chosen to help isolate what in some cases may be rather subtle SST-drought linkages from relatively short model integrations. In the case of the trend, the pattern is scaled by \pm 1 standard deviation, which effectively forces the model with the 40-yr averages of the trend anomalies at the beginning ( -1 standard deviation) and end ( +1 standard deviation) of the 1901-2004 time period. An additional experiment was proposed to force the models with a globally uniform

\footnotetext{
${ }^{1}$ We note that there is considerable sensitivity of the trend pattern to the time period of interest and the datasets used particularly regarding the contribution from the Pacific (e.g., Vecchi et al. 2008; Chen et al. 2008).

${ }^{2}$ The NOAA/GFS experiments were somewhat shorter (35 yr).

${ }^{3}$ Masks were applied to REOFs two and three to zero out any small values that, for the Pacific pattern, fall outside the Pacific and Indian Oceans, and that, for the Atlantic pattern, fall outside the Atlantic Ocean.
}

SST warming distribution equal to the global mean of the positive trend pattern $\left(0.16^{\circ} \mathrm{C}\right)$.

It is important to note that the anomaly patterns are fixed in time and therefore do not have an annual cycle. The absence of a seasonal cycle in the forcing arguably diminishes the importance of winter SST anomalies relative to summer SST anomalies, especially for tropical Pacific variability, because observations indicate that winter anomalies tend to be much larger in magnitude compared to summer anomalies (e.g., An and Choi 2008). There is, however, an annual cycle in the full SST forcing fields as a result of the annual cycle in the climatological SST on which the prescribed anomaly patterns are superimposed. The SST forcing is repeated with no interannual variability for each year of each experiment, but the models still generate interannual variability resulting from unforced "weather noise" associated with the internal dynamics of the models. We will assess the magnitude of the forced response to the prescribed SST anomalies relative to the magnitude of the unforced interannual variability.

The nine baseline experiments of the project consist of the runs in which the models are forced with all eight combinations of the Pacific and Atlantic patterns shown in Fig. 1, as well as the control run forced only with the monthly varying climatological SST. These are summarized in Table 1 according to the different combinations of patterns and phases of the forcing. For example, PwAc indicates that a model is forced with the warm phase of the Pacific and the cold phase of the Atlantic patterns. In addition to those shown in Table 1 , runs were proposed in which the models are forced with either the positive or negative trend pattern, both alone, or superimposed on selected combinations of the Pacific and Atlantic patterns.

A number of other auxiliary experiments were proposed to isolate further various mechanisms and time scales of variability. Some isolate the role of the tropics, while others attempt to separate the contributions from ENSO and lower-frequency Pacific variability. Another set of experiments were formulated to assess the impact of land-atmosphere feedbacks. These additional experiments are described in the appendix. Another related and important set of experiments consist of Atmospheric Model Intercomparison Project (AMIP)-style simulations (Gates et al. 1999). These are simulations (typically several decades long) in which the models are forced by the historical record of observed SSTs. While the focus of the runs described here is on understanding mechanisms and model sensitivity to idealized SST forcing, the AMIP runs are important in that they facilitate model validation by allowing more direct comparisons of the results with observations. 
TABLE 1. The different combinations of the Pacific and Atlantic SST anomaly patterns used to force the GCMs. Here w refers to the warm phase of the pattern (with a 2 standard deviation weight) and c refers to the cold phase (with a 2 standard deviation weight). Also, $n$ denotes neutral, indicating that the pattern has zero weight. In particular, the PnAn experiment denotes the control run forced with the annually varying climatological SST.

\begin{tabular}{lccc}
\hline \hline & $\begin{array}{c}\text { Warm } \\
\text { Atlantic }\end{array}$ & $\begin{array}{c}\text { Neutral } \\
\text { Atlantic }\end{array}$ & $\begin{array}{c}\text { Cold } \\
\text { Atlantic }\end{array}$ \\
\hline Warm Pacific & PwAw & PwAn & PwAc \\
Neutral Pacific & PnAw & PnAn & PnAc \\
Cold Pacific & PcAw & PcAn & PcAc \\
\hline
\end{tabular}

\section{c. Contributing groups and models}

A number of groups have participated in this project by contributing model runs. While only a few groups have carried out all of the proposed runs, most have done at least the baseline set of experiments defined in Table 1. The National Aeronautics and Space Administration's (NASA's) Global Modeling and Assimilation Office (GMAO) contributed runs made with version one of the NASA Seasonal-to-Interannual Prediction Project (NSIPP-1) AGCM. The National Oceanic and Atmospheric Administration's (NOAA's) Climate Prediction Center, with support from the Climate Test Bed, contributed runs made with the Global Forecast System (GFS) AGCM, and NOAA's Geophysical Fluid Dynamics Laboratory (GFDL) contributed runs made with the Atmosphere Model version 2.1 (AM2.1) AGCM. The Lamont-Doherty Earth Observatory of Columbia University contributed runs made with the National Center for Atmospheric Research (NCAR) Community Climate Model, version 3.0 (CCM3.0) AGCM, and NCAR con- tributed runs made with the Community Atmosphere Model, version 3.5 (CAM3.5) AGCM. An additional set of runs was made by Center for Ocean-Land-Atmosphere Studies (COLA)/University of Miami with the coupled (atmosphere-ocean) Community Climate System Model, version 3.0 (CCSM3.0) employing a novel adjustment technique to nudge the coupled model toward the imposed SST forcing patterns. The main characteristics of the models of interest and some of the relevant references are presented in Table 2.

\section{Results}

This section provides an overview of the results from the five AGCMs. Results from the coupled model (CCSM3.0) will be reported in a separate paper. The main focus here is on the annual mean response over the United States to the Pacific SST anomaly pattern. Additional diagnostics are presented that summarize the results from all eight combinations of the Pacific and Atlantic forcings shown in Table 1, as well as provide some assessment of the seasonality of the responses. The section ends with a brief overview of the responses to the trend pattern.

We begin by examining the ability of the AGCMs to reproduce the observed annual mean precipitation and height field climatologies based on the available AMIPstyle simulations (runs forced with observed SSTs) from each model for the period of 1980-98. We note that the results from the AMIP runs are quite similar to those from the control runs (PnAn; see Table 1, not shown). The AMIP runs, however, provide a cleaner, more direct comparison with observations than the control run, and therefore provide a more useful baseline assessment of model performance.

TABLE 2. Description of the models used in the drought working group simulations.

\begin{tabular}{|c|c|c|c|}
\hline Model (reference) & Resolution & $\begin{array}{l}\text { Convection scheme } \\
\text { (reference) }\end{array}$ & $\begin{array}{l}\text { Land surface model } \\
\text { (reference) }\end{array}$ \\
\hline $\begin{array}{l}\text { AM2.1 (Delworth et al. 2006; } \\
\text { GFDL Global } \\
\text { Atmospheric Model } \\
\text { Development Team 2004) }\end{array}$ & $2^{\circ} \times 2.5^{\circ}, \mathrm{L} 24$ & $\begin{array}{l}\text { Relaxed Arakawa-Schubert } \\
\quad \text { (Moorthi and Suarez 1992) }\end{array}$ & Milly and Shmakin (2002) \\
\hline $\begin{array}{l}\text { GFS, version } 2 \text { (Campana } \\
\text { and Caplan 2005) }\end{array}$ & $\mathrm{T} 62\left(\sim 2^{\circ} \times 2^{\circ}\right), \mathrm{L} 64$ & $\begin{array}{l}\text { Simplified Arakawa-Schubert } \\
\quad \text { (Grell 1993; Pan and Wu 1995) }\end{array}$ & Ek et al. (2003) \\
\hline $\begin{array}{l}\text { NSIPP-1 (Bacmeister et al. } \\
\text { 2000; Schubert et al. } \\
\text { 2002) }\end{array}$ & $3^{\circ} \times 3.75^{\circ}, \mathrm{L} 34$ & $\begin{array}{l}\text { Relaxed Arakawa-Schubert } \\
\text { (Moorthi and Suarez 1992) }\end{array}$ & $\begin{array}{l}\text { Mosaic (Koster and } \\
\text { Suarez 1996) }\end{array}$ \\
\hline $\begin{array}{l}\text { CCM3.0 (Kiehl et al. 1998; } \\
\text { Seager et al. 2005) }\end{array}$ & $\begin{array}{l}\mathrm{T} 42\left(\sim 2.8^{\circ} \times 2.8^{\circ}\right), \text { with } 18 \\
\quad \text { hybrid sigma levels }\end{array}$ & $\begin{array}{l}\text { Zhang and McFarlane } \\
\text { (1995) and Hack (1994) }\end{array}$ & Bonan (1996) \\
\hline $\begin{array}{l}\text { CAM3.5 (online at http:// } \\
\text { www.ccsm.ucar.edu/ } \\
\text { models/atm-cam/) }\end{array}$ & T85, with 27 hybrid sigma levels & Oleson et al. (2008) & $\begin{array}{l}\text { Community Land Model } \\
\text { (Oleson et al. 2008; } \\
\text { Stockli et al. 2008) }\end{array}$ \\
\hline CCSM3.0 (Collins et al. 2006) & $\begin{array}{l}\text { AGCM: T85, with } 26 \text { levels; OGCM: } \\
1^{\circ} \times 1^{\circ} \text {, telescoping to } 1^{\circ} \times 1 / 2^{\circ} \text { in } \\
\text { the deep tropics with } 40 \text { levels }\end{array}$ & $\begin{array}{l}\text { Zhang and McFarlane } \\
\text { (1995) }\end{array}$ & Community Land Model \\
\hline
\end{tabular}


CCM3

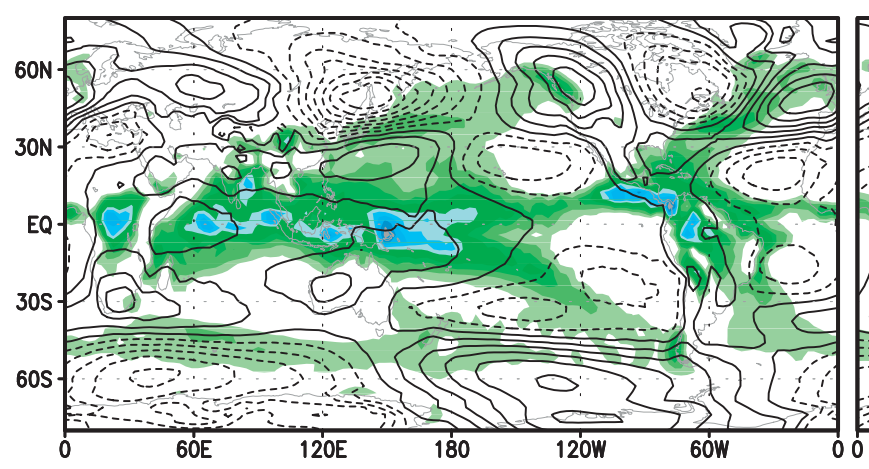

GFS

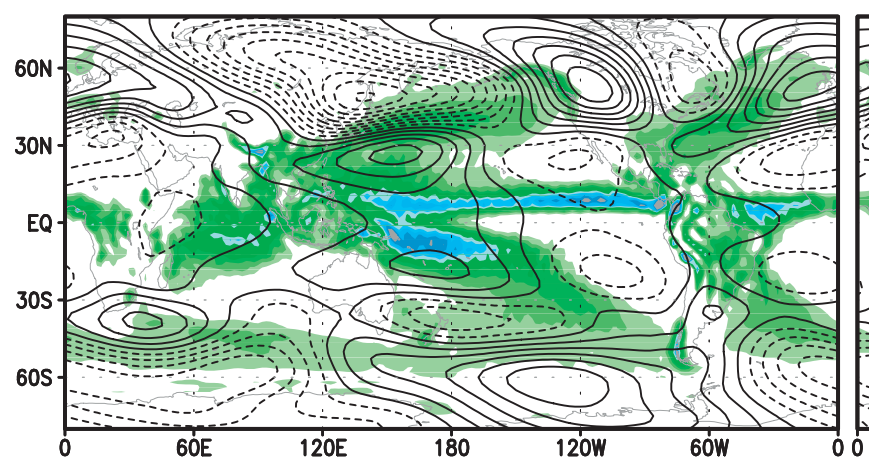

CAM3.5
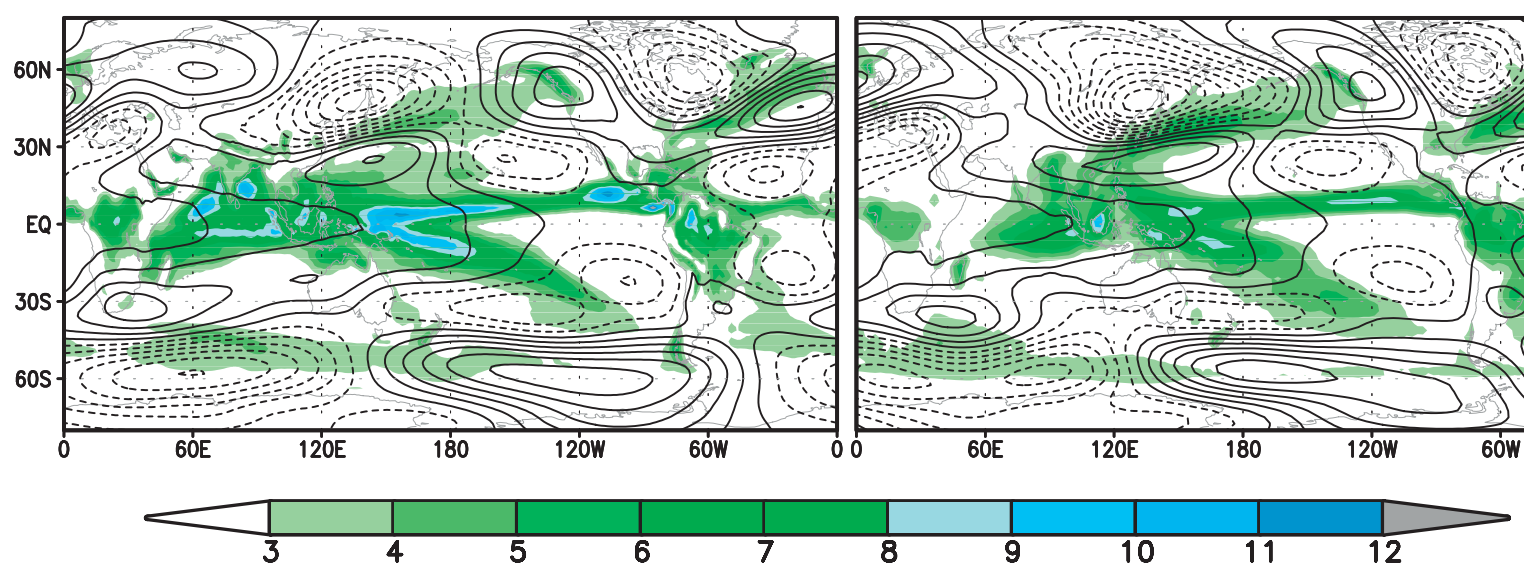

FIG. 2. Annual mean precipitation (shaded) and 200-mb eddy height field (contoured) averaged over the years of 1980-98. The model results are from AMIP-style runs from each model (runs forced by observed SSTs). (bottom right) For the observations, the precipitation is from the Global Precipitation Climatology Project (GPCP; Adler et al. 2003) and the height fields are from the National Centers for Environmental Prediction (NCEP)-NCAR reanalyses (Kalnay et al.1996). The time period was chosen in order to have a common set of years for each model. The contour interval for the height field is $20 \mathrm{~m}$ (negative values are dashed and the zero line is the first solid contour). Precipitation is in millimeters per day.

All of the models produce quite reasonable annual mean stationary wave and precipitation patterns (Fig. 2). There are, however, differences in the details, including such features as the strength of the Pacific ITCZ (cf. the
NSIPP-1 and GFS results) and, of particular interest here, the strength and orientation of the height anomalies over the Pacific-North American region. In general, the models tend to overestimate precipitation in the western 
Pacific and Atlantic warm pool regions compared with observations. Most models also tend to underestimate the strength and eastward extent of the East Asian trough. The GFS model is the exception, showing a deeper trough together with a stronger ridge over North America compared with the observations and the other models. An interesting feature is the wave train that appears to emanate from the central tropical Pacific and extends across North America into the Atlantic. It appears to be responsible for modifying the structure and amplitude of the west coast ridge and the trough over eastern North America. This feature is evident in the observations and all of the models except GFS, where it is at most very weak. The extent to which such differences in the climatological stationary wave pattern impact the response to the SST anomalies is unclear. This issue will be revisited later in the discussions of the model responses.

Figure 3 provides an overview of the agreement between the models with respect to the annual mean responses to the eight combinations of the Pacific and Atlantic SST patterns. The results are presented as spatial correlations between the 10 different combinations of the five models (model 1 correlated with model 2, model 1 correlated with model 3 , etc.). The scatter of the 10 different combinations gives a sense of the full range of agreement or disagreement between the various models for any one forcing pattern. The ordinate is the correlation based on precipitation, and the abscissa is the correlation based on the 200-mb height. Figure 3a shows the results for the global and annual mean distributions. Here we limit the comparisons to the four basic individual Pacific and Atlantic forcing patterns (no combinations of forcing patterns) to better highlight the differences in the level of agreement between responses to the Pacific and Atlantic forcing patterns. The global annual mean results show a number of interesting features. First, it is clear that the models are in much stronger agreement regarding the responses to the Pacific forcing (dark colors), compared with the response to the Atlantic forcing (light colors). It is also clear that in general there is more agreement in the height response than in the precipitation response (almost all points lie below the $45^{\circ}$ line). For plots in Figs. $3 b-f$ the results are shown for all eight forcing patterns. The tropical results (Fig. 3b) show generally very strong agreement in the height response for all forcing combinations. The response to the Atlantic forcing shows relatively weak precipitation correlations (generally less than 0.6 ), while the response to the combined (Pacific and Atlantic) forcing patterns exhibit correlations that are comparable to the Pacific forcing results, a reflection of the dominance of the Pacific forcing. There are also some interesting seasonal differences in the global correlations. The results for
December-February (DJF; Fig. 3c) show a tendency for greater agreement in the precipitation response than the height response for the cold Pacific, while the opposite is true for the warm Pacific cases. This seems to reflect a weaker and less robust height response to a cold Pacific compared with a warm Pacific forcing. The height response appears to be most robust during March-May (MAM; Fig. 3d), while June-August (JJA) shows overall the smallest precipitation correlations. The response to the Atlantic appears to be the most robust (and comparable to the response to the Pacific) during SeptemberNovember (SON; see Fig. 3f).

We next turn to a more in-depth comparison of the annual mean global 200-mb height and precipitation responses. A comparison of the spatial distributions of the response to the warm Pacific (Fig. 4) shows considerable large-scale similarity among the models (as expected from the correlations in Fig. 3). In particular, all models show the well-known (ENSO type) horseshoe-shaped precipitation response, with a positive precipitation anomaly in the central tropical Pacific surrounded by negative anomalies on either side of the equator. All of the models also show negative anomalies over Central America, northeastern South America, and the tropical Atlantic. There is general agreement in the height anomalies with wave trains emanating from the tropical Pacific and extending poleward into both hemispheres. The precipitation anomalies over North America appear strongly coupled to the detailed structure of the height anomalies. In particular, the spatial extent of the positive precipitation anomalies over the United States is linked to the orientation and strength of the negative height anomalies over the continent. The response over the United States will be discussed further (see reference to Fig. 6).

The global distributions of the precipitation responses to the cold Pacific (Fig. 5) are largely of an opposite sign compared with the responses to the warm Pacific. In particular, all of the models again show the familiar horseshoe-shaped precipitation response with a now negative precipitation anomaly in the central tropical Pacific surrounded by positive anomalies on either side of the equator. All of the models also show positive anomalies over Central America, northeastern South America, and the tropical Atlantic. The height anomalies also tend to be of an opposite sign, but in the extratropics they tend to be weaker than the response to the warm Pacific, reflecting an asymmetric response to the warm and cold Pacific forcings. All of the model responses show a tendency for a split ITCZ (also evident in the PwAn response) that is most pronounced in the GFDL and CAM3.5 models. All of the models also show a ridge over the North Pacific that extends eastward across the United States (though less so for the GFS model). 

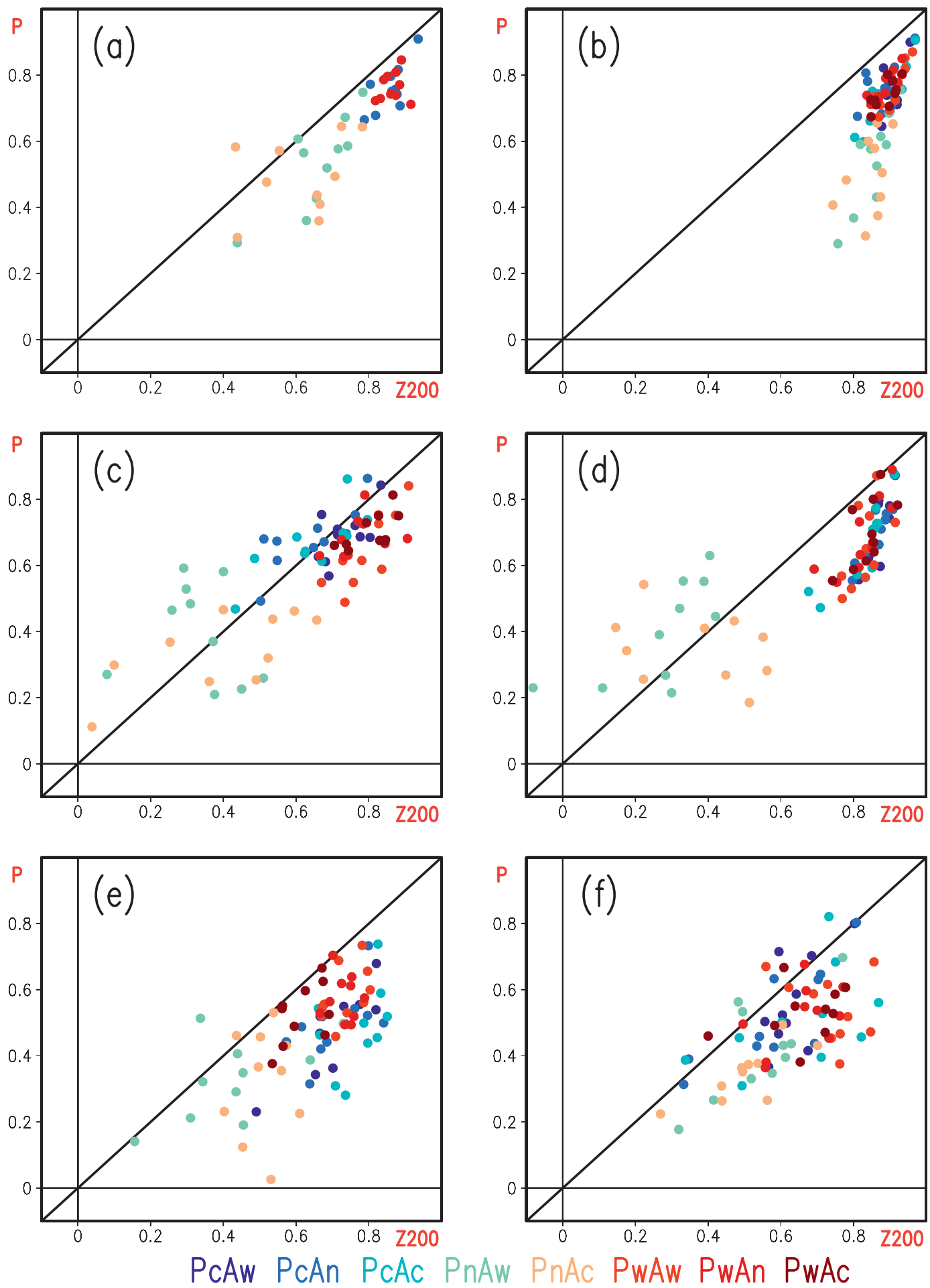

FIG. 3. Spatial correlations of precipitation anomalies (ordinate) vs spatial correlations of 200-mb height anomalies (abscissa) for the various combinations of models and for the eight combinations of forcing for the Pacific and Atlantic patterns: (a) global correlations of annual means, (b) tropical correlations $\left( \pm 30^{\circ}\right.$ latitude $)$ of annual means, (c) global correlations for DJF, (d) global correlations for MAM, (e) global correlations for JJA, and (f) global correlations for SON. See text for details. The colors refer to the forcing patterns indicated along the bottom of the plots. 
CCM3

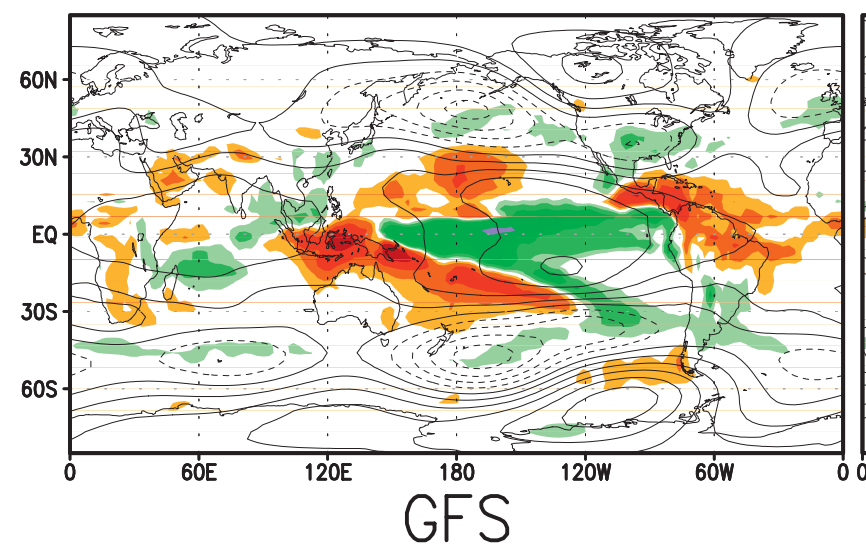

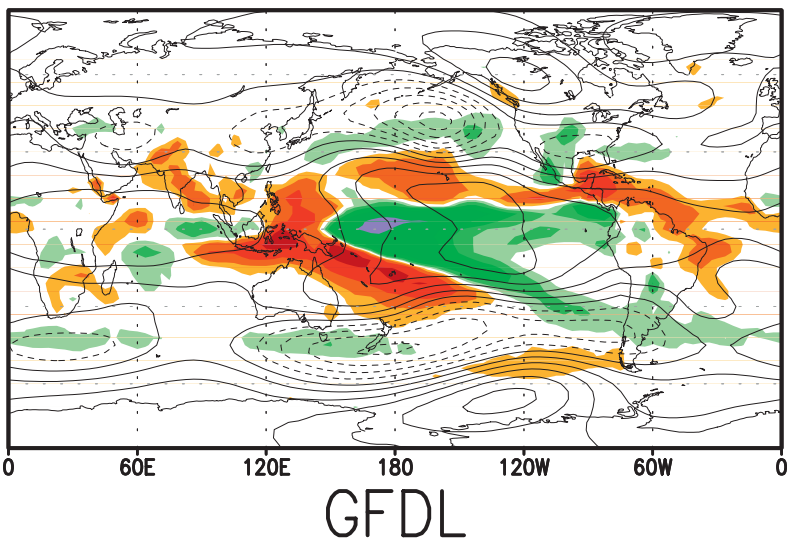

NSIPP1

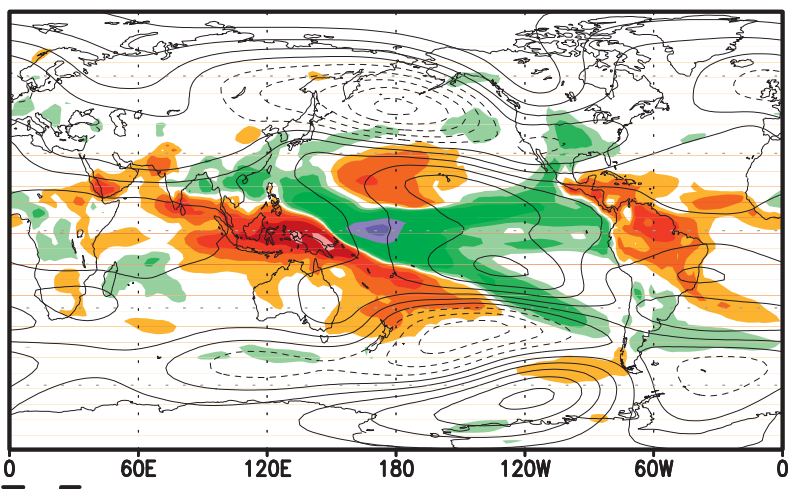

CAM3.5

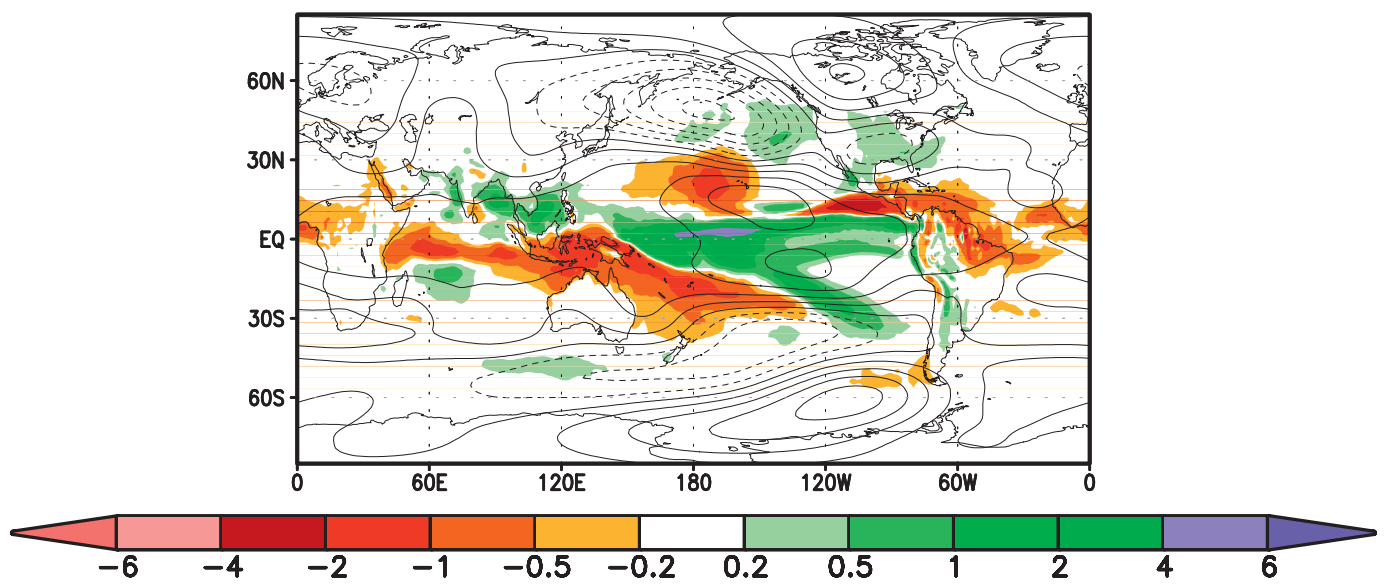

FIG. 4. Annual mean 200-mb height and precipitation responses to the PwAn SST anomaly pattern. The anomalies for each model are computed with respect to its annual mean response to a simulation in which the model is forced with climatological SSTs. See text for details on the SST forcing. Contour interval for height is $10 \mathrm{~m}$ (negative values are dashed and the zero line is the first solid contour). Precipitation is in millimeters per day.

Figure 6 provides a close up of the U.S. surface temperature $^{4}$ and precipitation responses to the PwAn and

\footnotetext{
${ }^{4}$ Here and elsewhere in the text the surface temperature over land refers to the skin temperature.
}

PcAn SST patterns. While all of the models show a tendency for wet conditions in response to PwAn forcing and dry conditions for the PcAn forcing, there are considerable differences among the models. For example, the NSIPP-1 response tends to be relatively localized 
CCM3

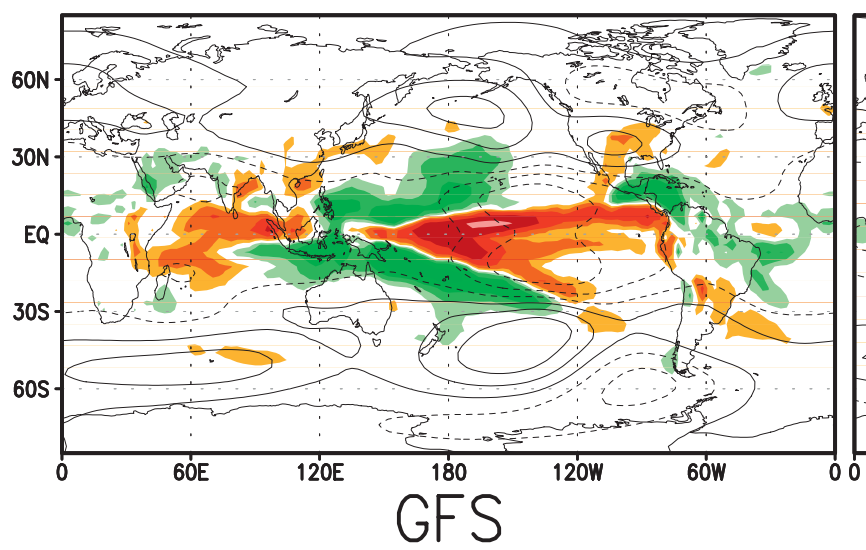

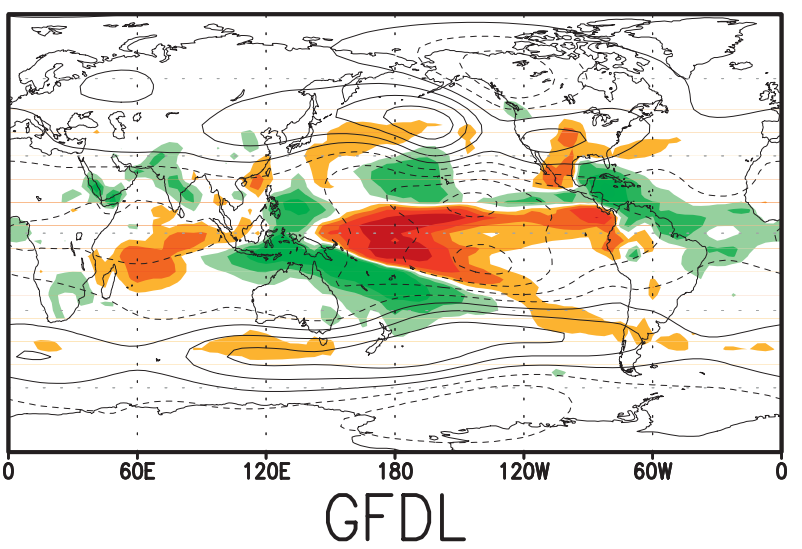

NSIPP1

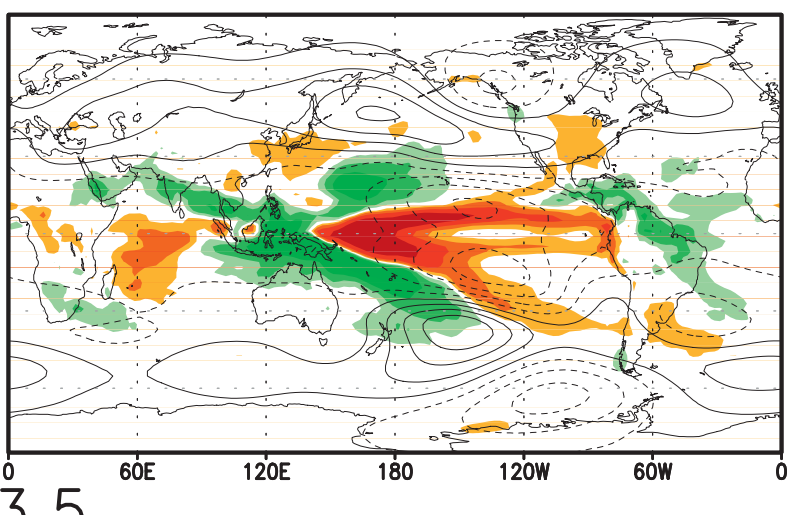

CAM3.5

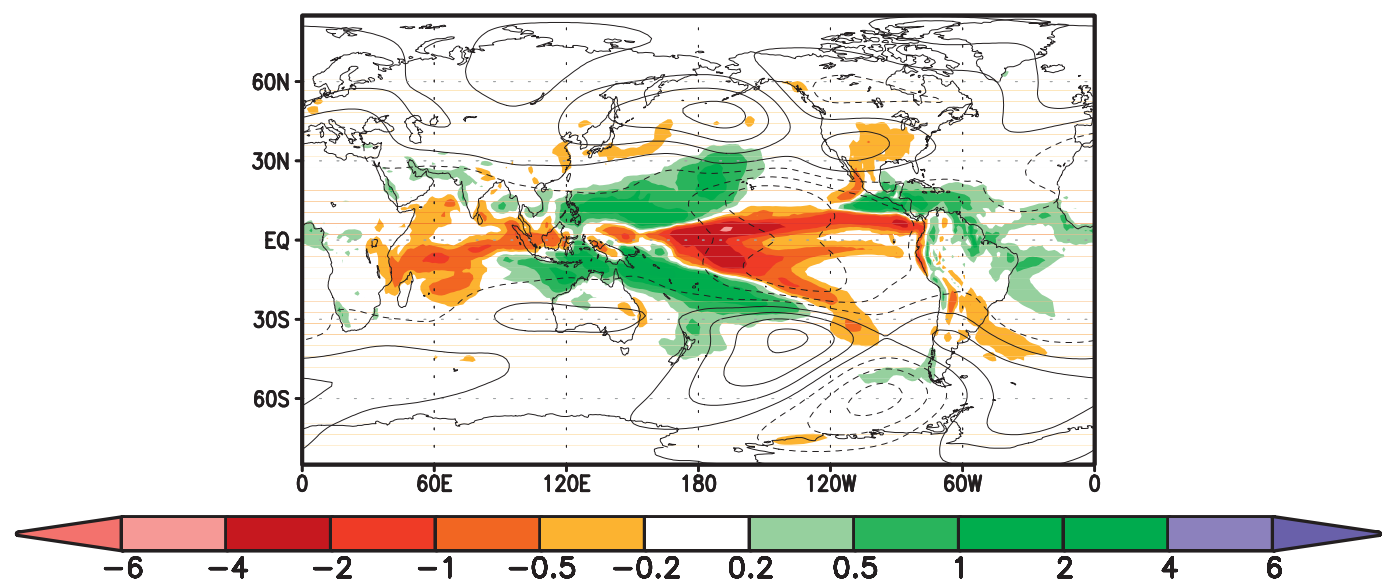

FIG. 5. Annual mean 200-mb height and precipitation responses to the PcAn SST anomaly pattern. The anomalies for each model are computed with respect to its annual mean response to a simulation in which the model is forced with climatological SSTs. See text for details on the SST forcing. Contour interval for height is $10 \mathrm{~m}$ (negative values are dashed and the zero line is the first solid contour). Precipitation is in millimeters per day.

over the central Great Plains (GP). On the other hand, the largest GFS response occurs along the southern and western tier of the states, while the other models tend to show more widespread precipitation anomalies. The magnitude of the precipitation response over the Great
Plains ranges between about 0.2 and $0.8 \mathrm{~mm}$ day $^{-1}$. For comparison, during the Dust Bowl drought the 1932-38 mean observed precipitation deficits over the Great Plains ranged from -0.2 to $-0.4 \mathrm{~mm}$ day $^{-1}$ (e.g., Schubert et al. 2004b). The surface temperature and precipitation 

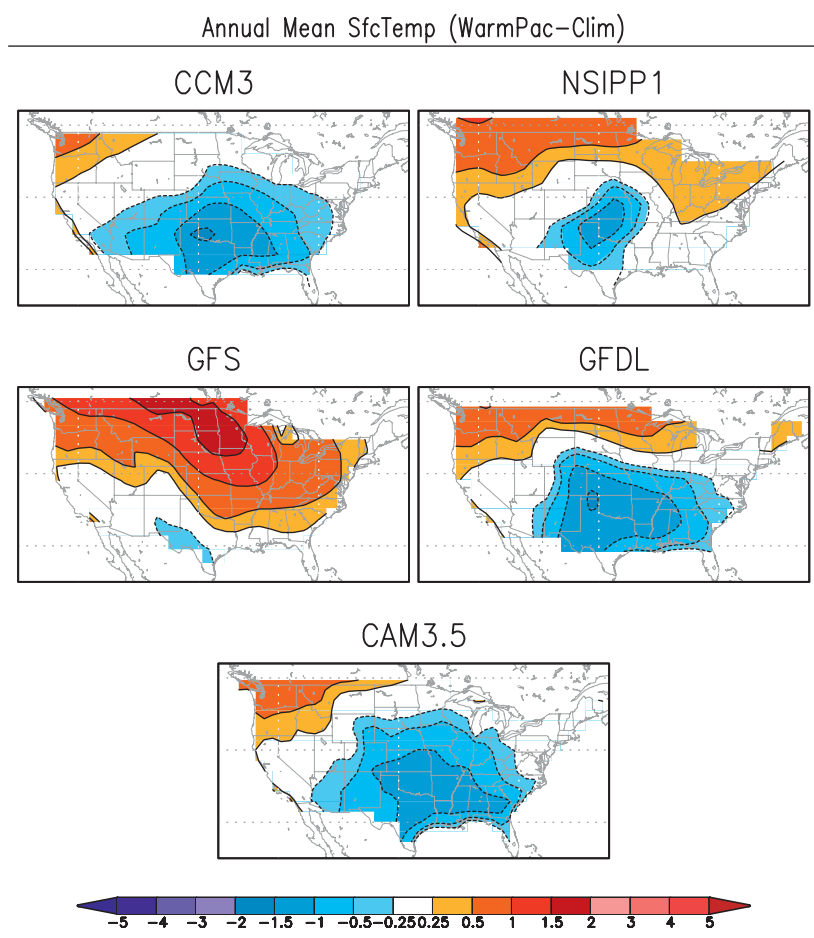

Annual Mean Precip (WarmPac-Clim)
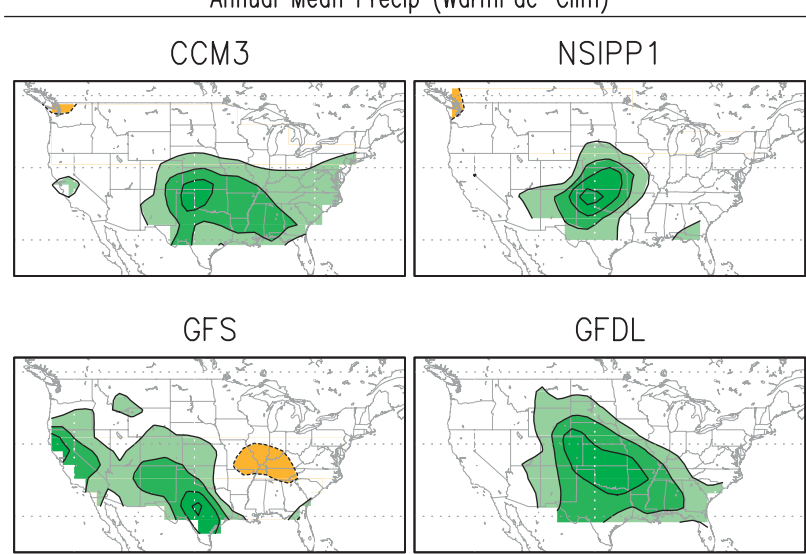

CAM 3.5
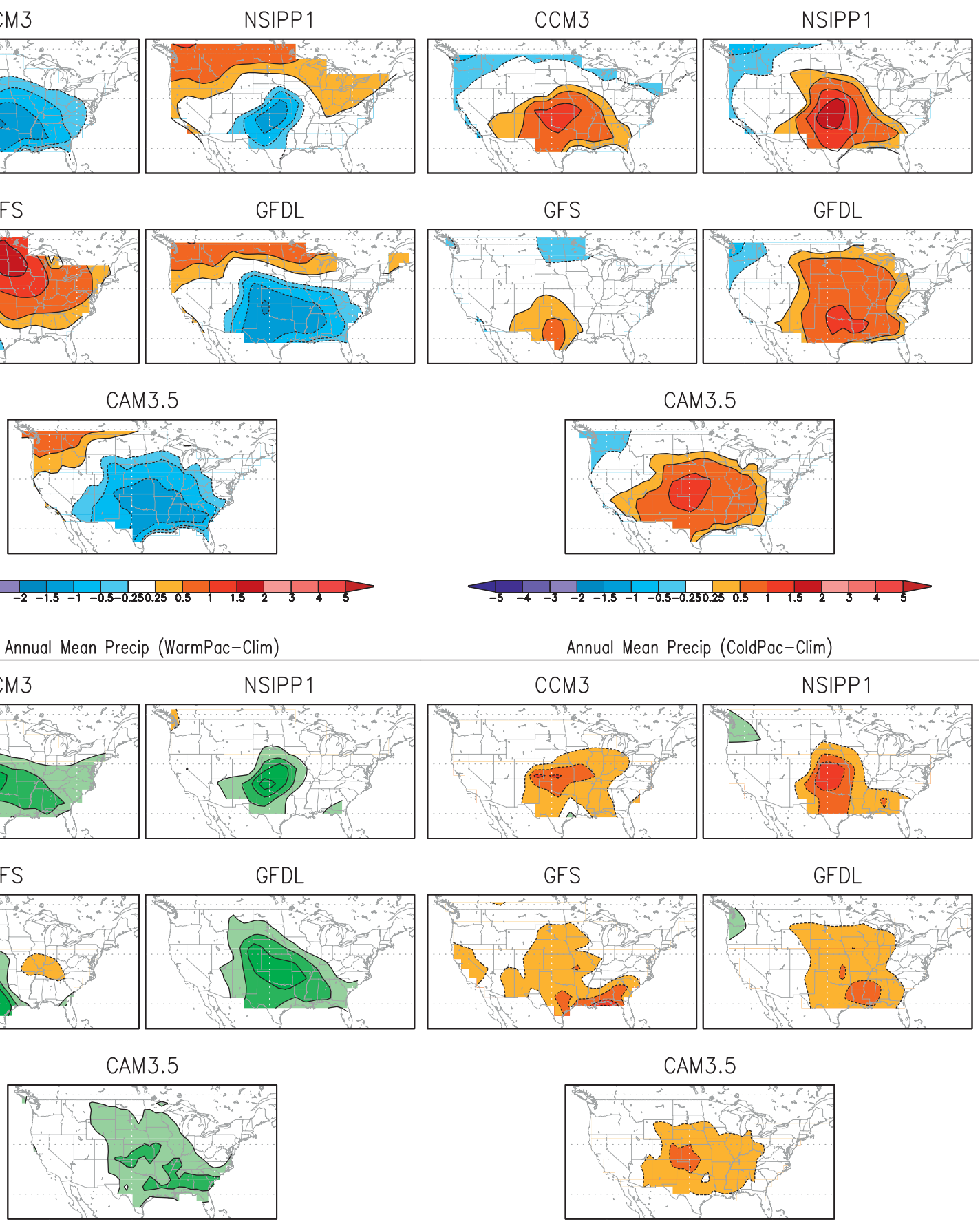

Annual Mean Precip (ColdPac-Clim)
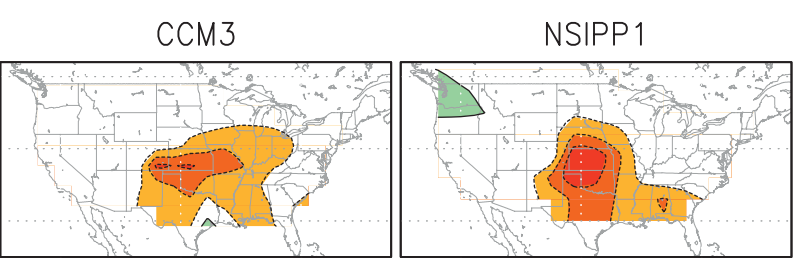

NSIPP 1

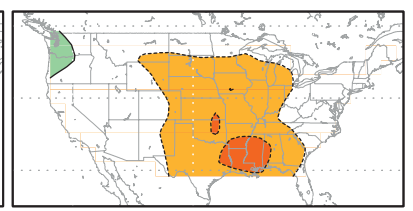

CAM3.5
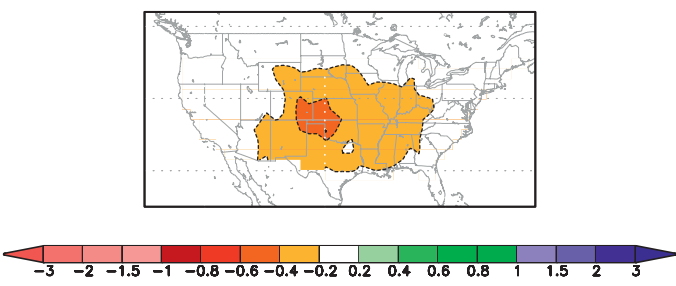

FIG. 6. Annual mean (top) surface temperature $\left({ }^{\circ} \mathrm{C} \mathrm{day}{ }^{-1}\right.$ ) and (bottom) precipitation ( $\mathrm{mm} \mathrm{day}^{-1}$ ) responses to the (left) PwAn and (right) PcAn SST anomaly patterns. The anomalies for each model are computed with respect to its annual mean response to a simulation in which the model is forced with climatological SSTs. See text for details on the SST forcing. 


\section{Annual Mean PtvsTt_GP (Pac-Clim)}

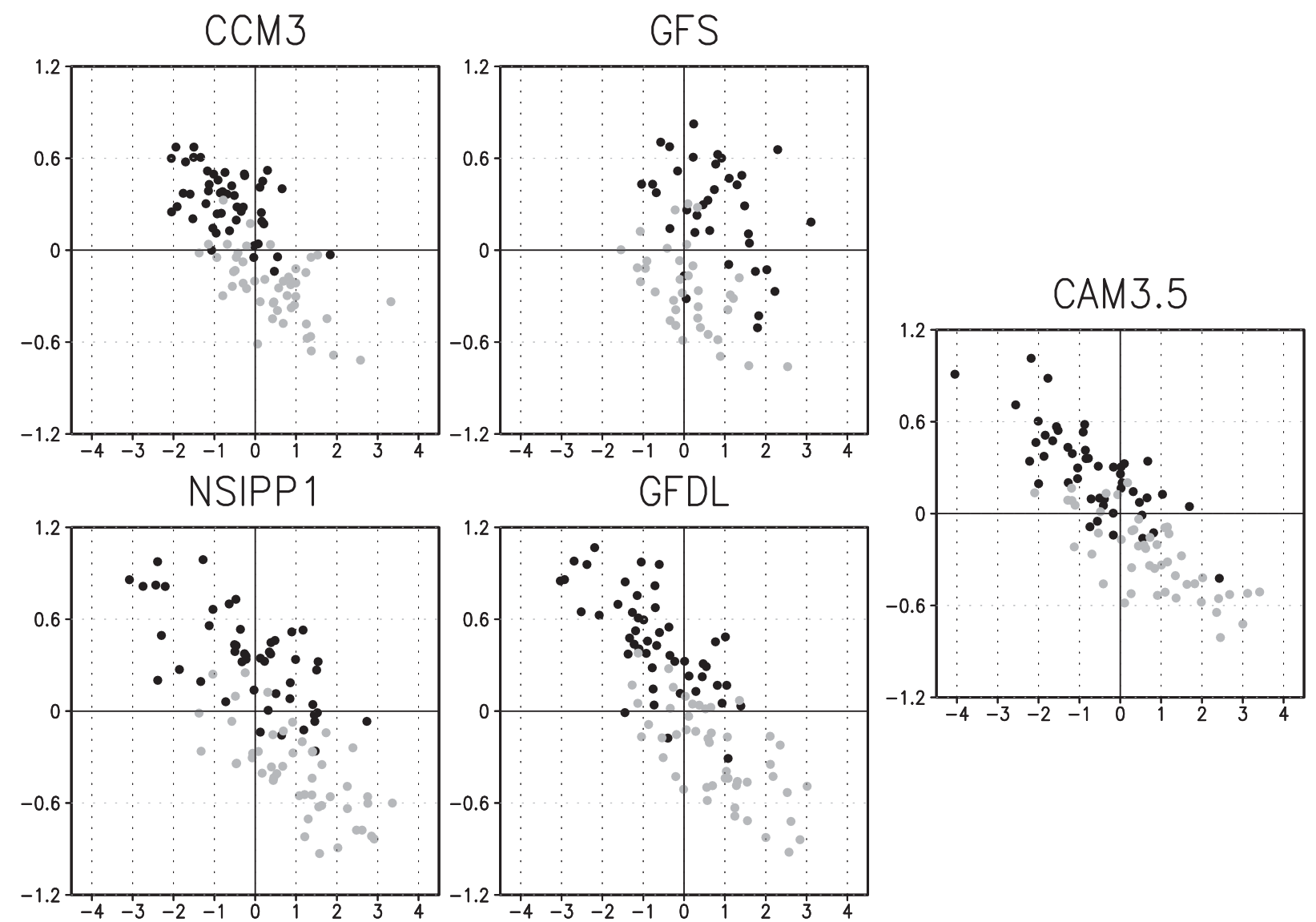

FIG. 7. Scatterplots of the Great Plains (see Fig. 9 for definition of region) annual mean precipitation (ordinate) vs surface temperature (abscissa) response to the PwAn (dark dots) and PcAn (light dots) SST anomaly patterns for the Great Plains area average. Each point represents 1 of 50 (35 yr for the GFS model) yr of each run.

anomalies tend to correspond in the sense that wet anomalies are associated with cold anomalies and dry anomalies are associated with warm anomalies. The temperature response of the GFS model is quite different from the other models, showing extensive warming over much of the United States (cooling is confined to the Southwest) in response to the PwAn forcing, with only a slight warming over the southern Great Plains (sGP) in response to the PcAn forcing.

The linkage between the surface temperature and precipitation responses over the central United States is explored further in Fig. 7. All of the models show a very robust precipitation response with a clear separation of the wet (PwAn) and dry (PcAn) years. There is an overall tendency for a negative relationship between the precipitation and surface temperature anomalies. The exception is again the GFS model, for which the response to the PwAn pattern is generally characterized by positive temperature anomalies and enhanced precipitation. The negative relationship between the annual mean temperature and precipitation responses is largely a reflection of the warm season responses (primarily JJA, but also in some cases MAM and SON; not shown), and presumably reflects a strong tie between the atmosphere and land surface during the warm season for all but the GFS model. ${ }^{5}$ Simply put, wetter conditions tend to lead to higher evaporative cooling and thus cooler air temperatures.

We next summarize the annual mean responses over the continental United States to the eight different combinations of the Pacific and Atlantic forcing patterns. Figure 8a shows the precipitation responses.

\footnotetext{
${ }^{5}$ The GFS model is in fact known to have a relatively weak land-atmosphere coupling strength (Koster et al. 2006).
} 

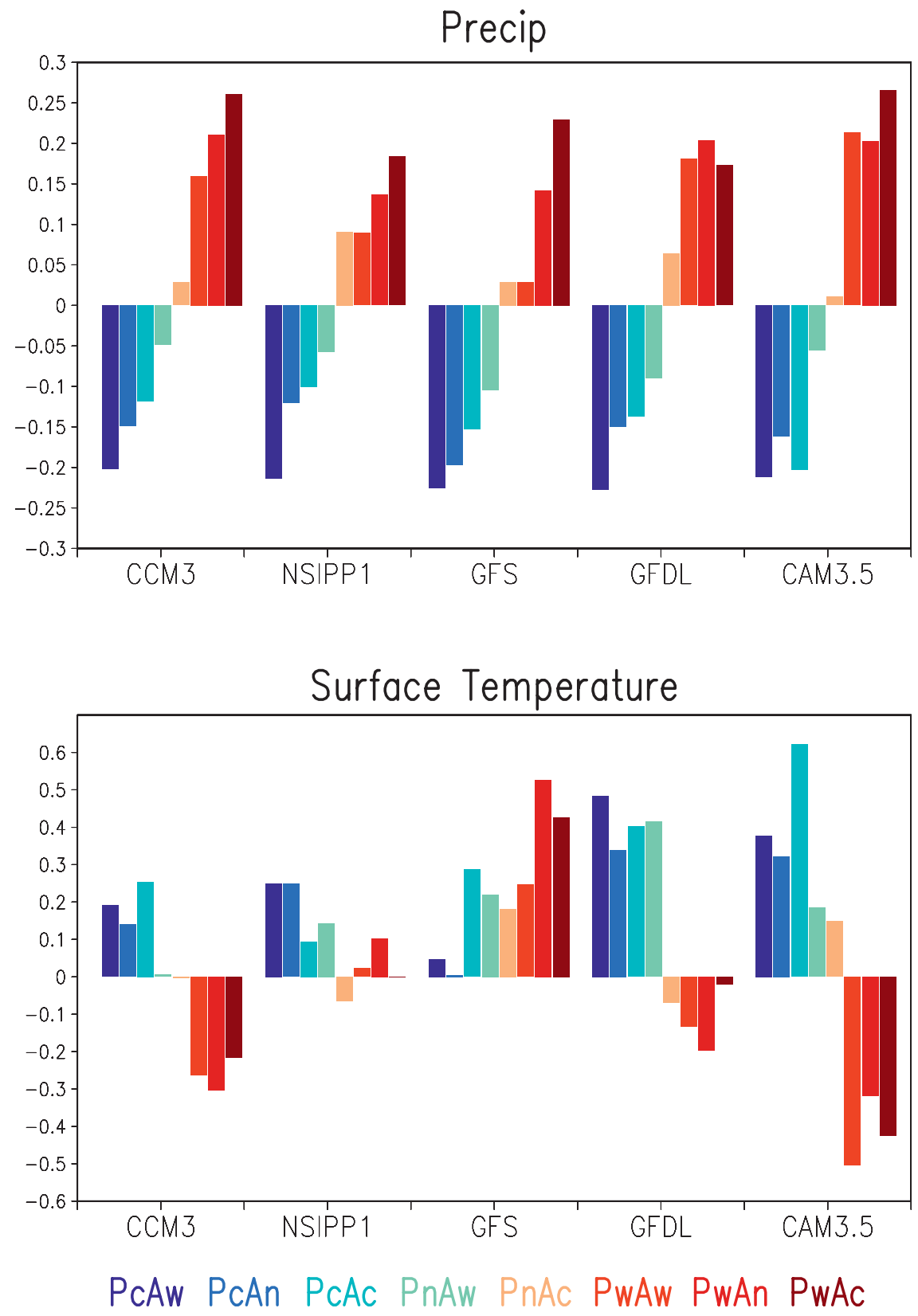

FIG. 8. The annual and continental U.S. mean responses for (a) precipitation $\left(\mathrm{mm} \mathrm{day}^{-1}\right.$ ) and (b) surface temperature $\left({ }^{\circ} \mathrm{C}\right)$ for all eight combinations of the Pacific and Atlantic patterns for the five AGCMs (see Table 1).

There is agreement among the models that a cold Pacific results in a reduction of precipitation, whereas a warm Pacific produces precipitation increases. Also, there is general agreement that a warm Atlantic leads to reduced precipitation whereas a cold Atlantic leads to increased precipitation, though with substantially smaller amplitudes, especially for the response to the cold Atlantic. Overall, the models agree that the combination of a cold Pacific and warm Atlantic (PcAw) tends to produces the largest precipitation deficits, whereas the combination of a warm Pacific and cold Atlantic (PwAc) tends to produce the largest precipitation surpluses. There is somewhat less agreement for the surface temperature responses (Fig. 8b), with generally positive (negative) temperature anomalies associated with precipitation deficits (surpluses), but that is not the case for the GFS model (and to a lesser degree the NSIPP-1 model), which shows strong, warm anomalies associated with 


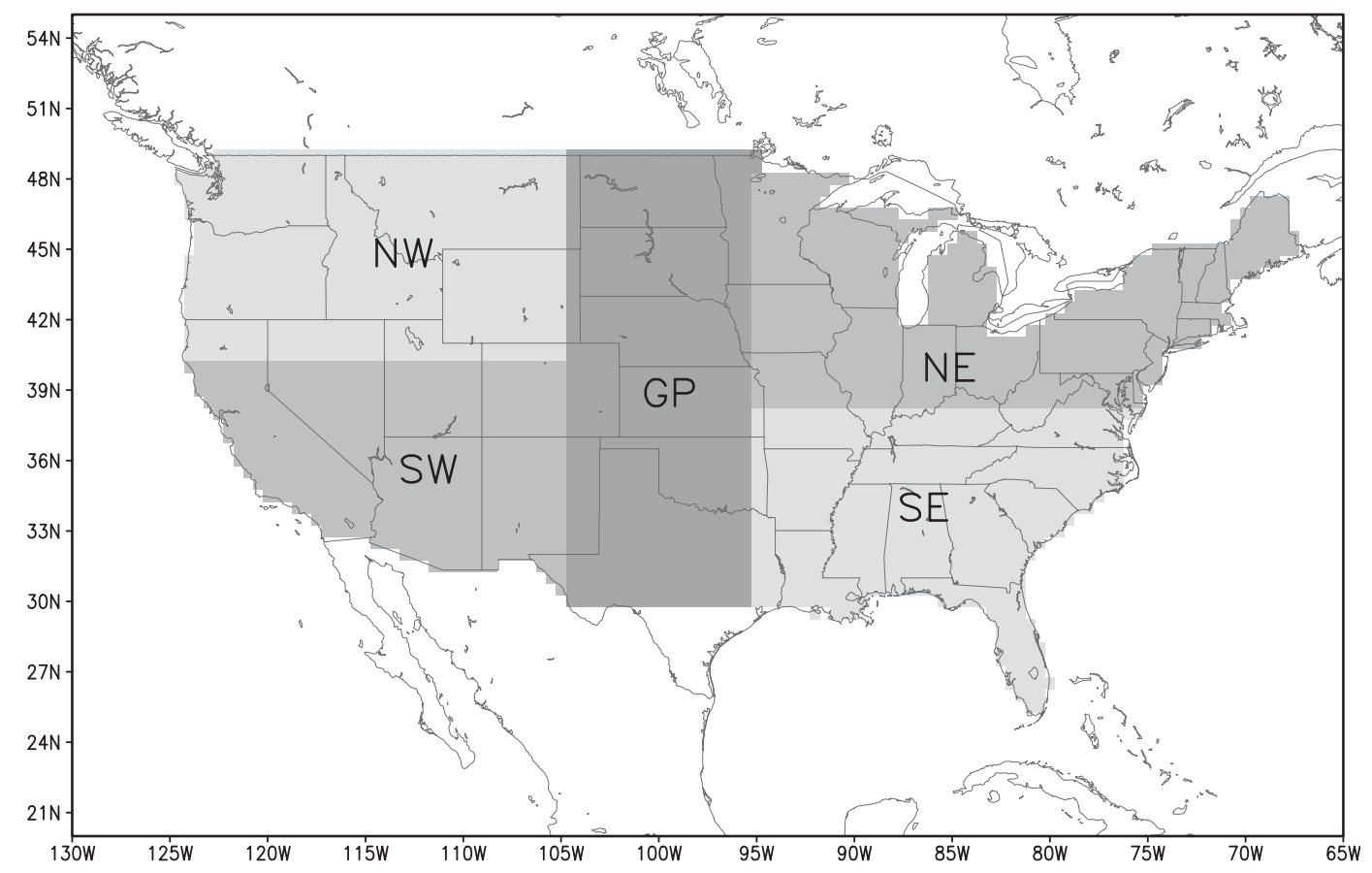

FIG. 9. The regions of the United States used to form the averages in Figs. 7, 10, and 11. The GP region is further divided (at $40^{\circ} \mathrm{N}$ latitude) into the $\mathrm{nGP}$ and the sGP regions.

enhanced precipitation (consistent with the previous results).

The scatter in the year-to-year responses to the Pacific forcing shown in Fig. 7 for the Great Plains shows the extent to which internal weather variability obscures the signal forced by the SST anomalies. This can be formalized in terms of the quantity

$$
R=\frac{(\bar{x}-\bar{y})}{s_{x y}},
$$

where $x$ and $y$ represent seasonal values from the experiment and control runs respectively, and the overbar denotes a 50-yr (35 yr, for the GFS model) mean. Also, $s_{x y}^{2}=\left(s_{x}^{2}+s_{y}^{2}\right) / 2$, where $s_{x}^{2}$ and $s_{y}^{2}$ are the variance estimates of $x$ and $y$, respectively. The mean difference between the experiment and control (the numerator) is a measure of the signal, so that $R$ measures the size of the signal in units of standard deviation and can be viewed as the signal-to-noise ratio associated with the response.

Figure 9 shows the definitions of the various regions of the United States. Figure 10 shows $R$ for the precipitation response to the PwAn and PcAn forcing patterns for each season and all models over the different regions. The results for the U.S. average (top-left panel) show significant (at the 5\% level) responses throughout most of the year for both the PwAn and PcAn forcing patterns. Somewhat surprisingly the signal-to-noise ratio is smallest (in fact only marginally significant) in DJF and largest during MAM/April-June (AMJ), when it reaches values of 1.5 or greater. We note that a very similar seasonality is found in the signal itself, so the results do not simply reflect a greater noise during the winter season. We caution however that, as indicated in section 2 , there is no seasonal cycle in the prescribed forcing, whereas observed SST anomalies are largest in winter.

A comparison of the results for PwAn and PcAn shows that magnitudes are largely comparable with perhaps somewhat weaker $R$ values (characterized by less agreement among the models) for the cold Pacific case. The results for the United States as a whole reflect, to a large extent, the results in the Great Plains and Southwest, particularly the southern Great Plains. The northern Great Plains (nGP) show a similar seasonality, but have more modest signal-to-noise ratios. The Northwest United States has the largest ratios during the northern spring and summer, while there is little evidence of a significant response in the Northeast. The Southeast has the largest signal-to-noise ratios during winter and spring, with minimal (not significant) responses during the summer season. In general, the models have a very similar seasonality of the response. The GFS model shows a somewhat different behavior, especially for the northern Great Plains, where the significant response is largely confined to the cold phase during the fall. Also, in the Southeast the GFS model differs from the others in 

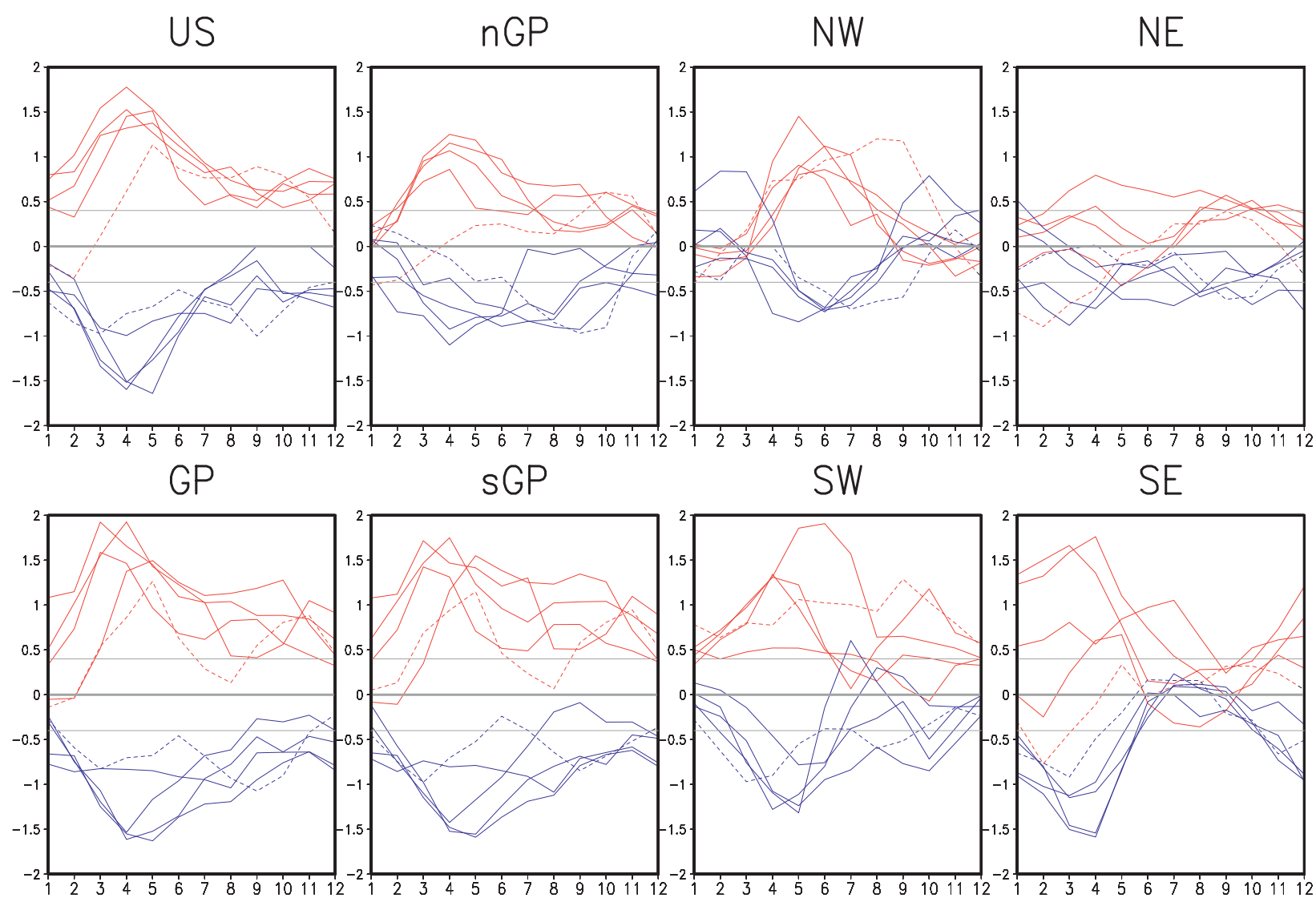

FIG. 10. Seasonality of the signal-to-noise ratios ( $R$; see text) of the 3 -month mean precipitation responses for each model over various regions of the United States to the Pacific warm (red curves) and cold (blue curves) SST anomaly pattern. The numbers along the abscissa refer to the center month of the 3-month means. Results are based on 50-yr simulations, except for the GFS model (dashed lines), which was run for $35 \mathrm{yr}$. See text for the definition of the signal-to-noise ratio. The thin horizontal lines denote the $5 \%$ significance levels based on a Student's $t$ test (for the GFS model the critical $t$ value is 0.49 ). Values are dimensionless.

that it shows little significant response to the warm phase (PwAn).

The $R$ values for the surface temperature response (Fig. 11) are substantially different from those for precipitation. In addition to having generally smaller amplitudes, there is considerable disagreement among the models regarding the seasonality and even the sign of $R$. For the continental United States as a whole (top-left panel) the response to the warm Pacific is significant for three models during the warm season (May-August), and large and significant for one model (GFS) during the cold season (March-May). The latter result reflects the unusual (compared to the other models) southward extension of the upper-level high in the GFS response (e.g., Fig. 4), and can be traced to the large signal-to-noise ratios in the northern tier of states (the second, third, and fourth top panels of Fig. 11). The response to the cold Pacific is for the most part insignificant or marginally significant, with the largest values occurring during late summer and fall. Excluding the GFS model, the most consistent results and the largest $R$ values occur for the southern tier of states (bottom panels of Fig. 11). For example, the southern Great Plains show a consistent warming signal during the warm season in response to a cold Pacific (with $R$ peaking in late spring), and cold anomalies in response to a warm Pacific beginning in late winter and extending into late summer. The southwest shows considerable asymmetry in the cold and warm Pacific responses, with only marginally significant responses to a cold Pacific, whereas the response to the warm Pacific shows significant $R$ values for two of the models during late spring and early summer. In the Southeast (bottom-right panel of Fig. 11), all of the models agree on having little skill during the late summer to early winter seasons in response to the cold Pacific. Four models show a tendency for a significant warming in late spring and early summer in response to the cold Pacific, while three models show cooling during the summer in response to the warm Pacific.

The overall level of agreement between the models can be quantified in terms of another signal-to-noise 

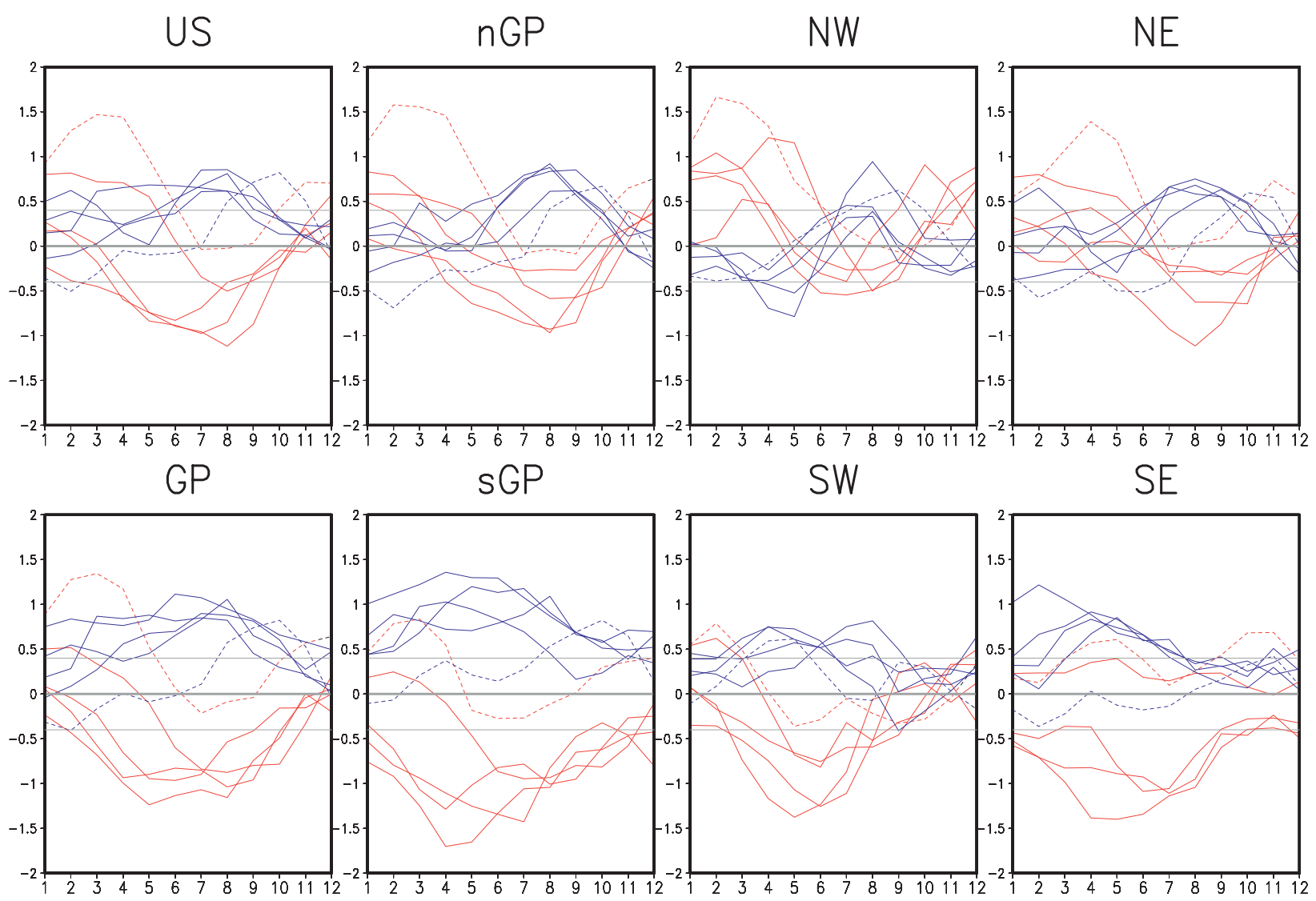

FIG. 11. Seasonality of the signal-to-noise ratios $(R$; see text) of the 3-month mean surface temperature responses for each model over various regions of the United States to the Pacific warm (red curves) and cold (blue curves) SST anomaly pattern. The numbers along the abscissa refer to the center month of the 3-month means. Results are based on 50-yr simulations, except for the GFS model (dashed lines), which was run for $35 \mathrm{yr}$. See text for the definition of the signal-to-noise ratio. The thin horizontal lines denote the $5 \%$ significance levels based on a Student's $t$ test (for the GFS model the critical $t$ value is 0.49).Values are dimensionless.

ratio that, in this case, measures the similarity of the $R$ values in units of standard deviation. In particular, we compute the ratio

$$
\Sigma=\left[\frac{\left|m_{R}\right|}{s_{R}}\right]
$$

where $m_{R}$ is the five-model average $R$ value for a given seasonal (3 month) mean, $s_{R}$ is the standard deviation of the five $R$ values, the vertical lines denote an absolute value, and the brackets denote an average over the 12 seasonal mean (3-month running mean) values. The results (presented in Table 3 ) highlight the substantially greater intermodel agreement in the $R$ values (larger $\Sigma$ ) for the precipitation responses compared with the surface temperature responses. For example, for the U.S. continental average response to the warm (cold) Pacific, the $\Sigma$ value for the precipitation response is about 5 (2) times larger than that for the surface temperature response. The results also quantify the asymmetries that exist in the level of agreement between the responses to the warm and cold Pacific. For example, over the Southeast United States the $\Sigma$ value for the precipitation (surface temperature) response to the cold Pacific is more than twice (3 times) that of the response to the warm Pacific.

Finally, we present a brief overview of the responses of the models to the trend pattern. The focus is on the surface temperature response to the positive trend pattern, and the results are compared to those from the companion set of runs in which the models were forced with a globally uniform SST warming of $0.16^{\circ} \mathrm{C}$. The precipitation response to the trend (not shown) is weak for all of the models, with anomalies that exceed $0.5 \mathrm{~mm} \mathrm{day}^{-1}$ in amplitude largely confined to a few locations in the tropical Pacific and Indian Oceans. The basic response of all of the models (left panels of Fig. 12) is a tendency for warming over most of the world's land areas, though there are substantial regional variations that differ between models. The GFS and GFDL models show the 
TABLE 3. The intermodel agreement in the $R$ values $(\Sigma)$ for precipitation and surface temperature. Here, $\Sigma$ is equal to the absolute value of the ensemble (five models) mean of $R$ divided by the standard deviation of $R$. The results are averaged over the annual cycle. The regions are defined in Fig. 9. Values are dimensionless. See text for details.

\begin{tabular}{|c|c|c|c|c|c|c|c|c|}
\hline & $\begin{array}{l}\text { United } \\
\text { States }\end{array}$ & $\begin{array}{l}\text { Great } \\
\text { Plains }\end{array}$ & $\begin{array}{c}\text { Northern } \\
\text { Great Plains }\end{array}$ & $\begin{array}{c}\text { Southern } \\
\text { Great Plains }\end{array}$ & Northwest & Southwest & Northeast & Southeast \\
\hline \multicolumn{9}{|l|}{ Precipitation } \\
\hline Warm Pacific & 3.71 & 2.67 & 1.57 & 2.44 & 1.61 & 2.58 & 1.36 & 1.20 \\
\hline Cold Pacific & 3.05 & 3.38 & 1.63 & 3.29 & 1.61 & 1.46 & 1.44 & 2.48 \\
\hline \multicolumn{9}{|c|}{ Surface temperature } \\
\hline Warm Pacific & 0.73 & 0.86 & 1.05 & 1.13 & 1.21 & 0.94 & 0.79 & 0.49 \\
\hline Cold Pacific & 1.38 & 1.97 & 1.34 & 2.25 & 1.10 & 1.72 & 1.02 & 1.60 \\
\hline
\end{tabular}

strongest warming, with especially large values (exceeding $0.5^{\circ} \mathrm{C}$ ) concentrated over North America and parts of Asia and Australia. CAM3.5 and CCM3 show the weakest warming, while the NSIPP-1 model shows intermediate values, with the largest warming occurring over North America. Focusing on North America, the GFS model shows strong warming over most of the continent (especially the western half), while the GFDL and NSIPP-1 models show warming that is more confined to the central and eastern United States. All but the GFS model show a substantial area of cooling spanning much of northern Canada and Alaska.

The impact of any regional variations in the SST trend forcing pattern can be deduced from comparisons with the runs forced by the globally uniform warming pattern $^{6}$ (right panels of Fig. 12). The comparison shows that many of the features of the response to the trend pattern are reproduced in the response to uniform warming. For example, some of the enhanced warming over North America in the GFS model, the enhanced warming over Asia in the GFDL model, and, more generally, the spatial pattern of the warming over much of Asia in all of the models is reproduced in the uniform warming case. The global spatial correlations between the responses to the trend and uniform warming of the annual mean values over land range from 0.34 for the NSIPP-1 model to 0.43 for the GFDL model. There is, however, a large seasonal variation in the correlations for some models. For example, for the GFDL model, the correlations range from 0.7 in March to 0.15 in July. A key difference between the two sets of responses over North America is that the cooling in northern Canada and Alaska noted earlier does not show up in the response to the uniform warming, indicating that this feature is primarily the result of regional variations in the SST trend pattern. Also, the localized warming responses over the United States in the GFDL and NSIPP-1 models are not reproduced in the case of uniform warming.

\footnotetext{
${ }^{6}$ This run was not done with CAM3.5.
}

\section{Summary and discussion}

The U.S. CLIVAR drought working group recently initiated a coordinated (multi-institutional and multimodel) effort to produce a set of idealized simulations designed to address fundamental questions regarding the physical mechanisms that link SST variations to regional drought, including an assessment of the role of land-atmosphere feedbacks. The set of experiments consist of multiyear simulations in which the models were forced by a number of idealized SST forcing patterns consisting of the leading rotated EOFs of SST variability on interannual and longer time scales. The main set of EOF forcing patterns include a global trend pattern, a Pacific ENSO-like pattern, and an Atlantic pattern that resembles the Atlantic multidecadal oscillation. Additional SST forcing patterns were designed to isolate ENSO and longer (decadal) time scales, and to isolate the influence of the tropical SST. A number of groups also ran experiments in which the land-atmosphere interactions were disabled by prescribing the soil moisture.

This paper, in addition to providing a general overview of the project, attempts to provide a broad-ranged assessment of the model results focusing on overall behavior and highlighting where the models tend to agree and disagree. Results are limited to the responses to the two leading Pacific and Atlantic forcing patterns, and the trend pattern. While showing some aspects of the global-scale response, much of the focus of this paper is on the responses over the continental United States.

A number of key results emerge from this initial analysis of the experiments. First, all of the models produce similar (though different in detail) precipitation anomalies over the continental United States in response to the Pacific forcing pattern, with a tendency for reduced precipitation when forced with a cold Pacific and a tendency for enhanced precipitation when forced with a warm Pacific. The response to the Atlantic pattern is not as robust as the response to the Pacific, though there is a tendency for reduced precipitation when forced with a warm Atlantic and a tendency for enhanced precipitation 


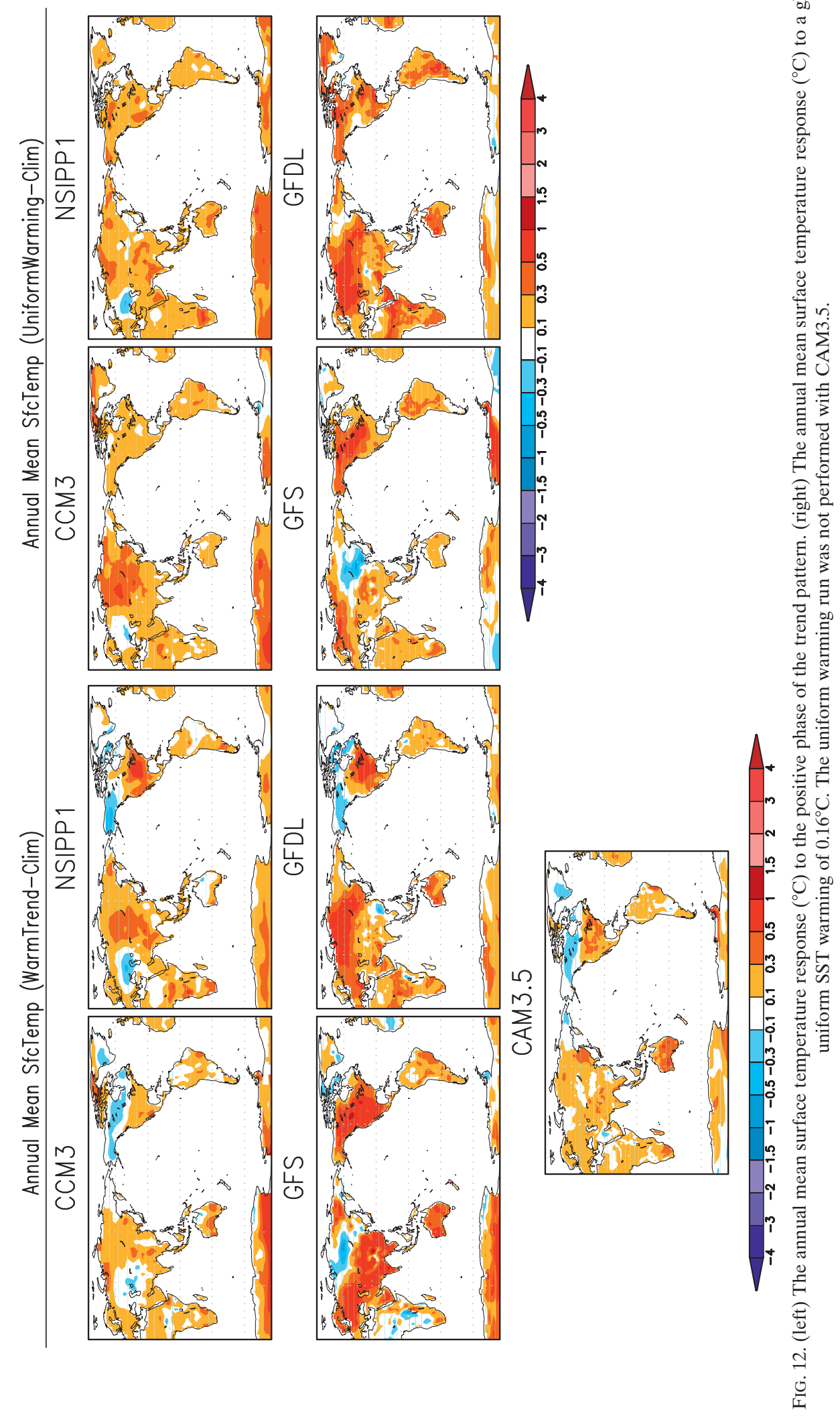


when forced with a cold Atlantic. There is general agreement among the models that the largest precipitation response over the continental United States tends to occur when the two oceans have anomalies of opposite signs. That is, a cold Pacific and warm Atlantic tend to produce the largest precipitation reductions, whereas a warm Pacific and cold Atlantic tend to produce the greatest precipitation enhancements.

The above results are to a large extent consistent with observationally based studies of the impact of SST anomalies on drought over the United States. For example, numerous observational studies have linked $\mathrm{Pa}$ cific SST variability (on ENSO and/or decadal time scales) to summertime precipitation and drought over the United States (e.g., Ting and Wang 1997; Nigam et al. 1999; Barlow et al. 2001). There is evidence that during AMO warm events (examples are the 1930s and 1950s) much of the United States experiences less-thannormal rainfall (e.g., Enfield et al. 2001). Also, McCabe et al. (2004), found that a number of U.S. droughts in the last few decades were associated with a positive AMO and a negative PDO, consistent with the model results.

The models tend to agree less on the area mean U.S. surface temperature response to both the Atlantic and Pacific forcing, though (with the exception of the GFS model) there is a general tendency for wet conditions to be associated with cold surface temperature anomalies and dry conditions to be associated with warm surface temperature anomalies. Differences in the land surface models very likely account for some of these model differences; however, the apparent sensitivity of the response over the United States to small (on planetary scales) shifts in the upper-level wave response to the SST forcing may also play a role. The fact that there is less sensitivity for the precipitation response is surprising, though it may be partly that the area mean of the more localized precipitation anomalies is less sensitive to shifts in the planetary wave forcing. The model differences are highlighted by the GFS response to the warm Pacific SST forcing, which tends to place the upper-level ridge of the response over North America considerably farther south compared to the other models, leading to warm surface temperature anomalies that extend well into the southern tier of the states.

Another key area of agreement among the models is in the seasonality of the signal-to-noise ratio $(R)$ of continental U.S. precipitation associated with the Pacific forcing. All of the models show that the largest $R$ values occur in spring with surprisingly small (not significant) $R$ values during winter. The above results for the United States as a whole reflect those in the Great Plains and the Southwest, particularly the southern Great Plains. In contrast to these results, the $R$ values of the surface temperature response to the Pacific forcing are generally lower and show considerably less agreement among the models. For the continental United States as a whole the GFS model stands out as having very high $R$ values during the cold season (March-May). This again appears to reflect the unusual (compared to the other models) southward extension of the upper-level high in the GFS response and can be traced to the large $R$ values that occur in the northern tier of states. For the other models, the most consistent results and the largest $R$ values occur for the southern tier of states, with, for example, the southern Great Plains showing a consistent warm anomaly during the warm season in response to a cold Pacific (with $R$ peaking in late spring), and cold anomalies in response to a warm Pacific beginning in late winter and extending into late summer.

The surface temperature response to the positive SST global trend forcing pattern shows substantial regional variations that are in part reproduced in runs forced with a globally uniform SST trend forcing. There is, however, substantial disagreement among the models in the regionality (e.g., the enhanced surface temperature response produced over North America by some of the models), highlighting the challenge of predicting regional impacts of global warming. The precipitation response to the trend forcing was found to be weak in all of the models.

The differences in the responses to the Pacific forcing pattern over the United States between the GFS and the other models are intriguing. Understanding these differences is important in view of the critical role that the GFS model (as part of the NOAA/Climate Forecast System) plays in seasonal prediction, and more generally regarding the increasingly important role that climate models play in providing information on the regional impacts of global climate variability and change. While it is beyond the scope of this paper to fully address the reasons for these differences, it appears likely that the differences in the stationary wave patterns play a role. The GFS model produces a very reasonable stationary wave pattern and arguably produces the most realistic overall structure of the Pacific trough and North American ridge (Fig. 2). The North American ridge is, however, stronger, and the trough to the east is considerably weaker compared with the other models and the observations. A preliminary linear model analysis of the NSIPP-1 model stationary waves (results not shown) indicates that the eastern North American trough is particularly sensitive to the heating in the western tropical Pacific, suggesting that the differences we see in the climatological precipitation in that region may play an important role. On the other hand, most of the other models produce a rather weak Pacific trough—a problem 
that very likely also contributes to deficiencies in the response over North America. Clearly more work is needed to not only improve our understanding of the sensitivity of stationary waves to the climatological forcing, but also to determine the extent to which that sensitivity translates into uncertainties in the extratropical response to SST anomalies.

The results of this initial analysis of the model experiments serve to highlight and quantify the important role of SST anomalies (especially those in the Pacific) in generating drought and pluvial conditions over the United States. The differences between the model results provide an assessment of the current uncertainties in our ability to model the global response to SST forcing (including the feedbacks associated with landatmosphere interactions) and reinforce the need to improve our climate models. We expect that these results, as well as those reported in the other contributions to this special issue on drought, will serve to stimulate further analysis of the simulations, as well as suggest new research on the physical mechanisms contributing to hydroclimatic variability and change throughout the world.

Acknowledgments. This project was carried out as part of a U.S. CLIVAR drought working group activity supported by NASA, NOAA, and NSF to coordinate and compare climate model simulations forced with a common set of idealized SST patterns. The authors thank NASA's Global Modeling and Assimilation Office (GMAO) for making the NSIPP-1 runs available, the Lamont-Doherty Earth Observatory of Columbia University for making their CCM3 runs available, NOAA's Climate Prediction Center (CPC)/Climate Test Bed (CTB) for making the GFS runs available, NOAA's Geophysical Fluid Dynamics Laboratory (GFDL) for making the AM2.1 runs available, the National Center for Atmospheric Research (NCAR) for making the CAM3.5 runs available, and the Center for Ocean Land Atmosphere (COLA) and the University of Miami's Rosenstiel School of Marine and Atmospheric Science for making the CCSM3.0 coupled model runs available. The NASA GMAO contributions to this project were supported by funding from the NASA Energy and Water Cycle Study (NEWS) program, and the NASA Modeling, Analysis and Prediction (MAP) Program.

\section{APPENDIX}

\section{Auxiliary Experiments}

In addition to forcing the models with the three main SST patterns presented in the text (the Pacific, Atlantic, and trend), the participating groups were encouraged to force their models with other patterns consisting of the tropical-only version of the Pacific and Atlantic patterns, and low- and high-frequency versions of the $\mathrm{Pa}$ cific SST patterns. Details about these patterns are discussed below.

To differentiate between the impacts of the tropics and extratropics, another set of SST "tropical" forcing patterns was produced based on the interannual Pacific and Atlantic patterns. For the Pacific case, this was done by linearly tapering the values to zero between $15^{\circ}$ and $21^{\circ}$ latitude. The taper is such that the full amplitude occurs at $15^{\circ}, 1 / 2$ of the full amplitude remains at $18^{\circ}$, and the anomaly is identically zero from $21^{\circ}$ latitude to the pole. Also, the meridional edges are such that the western boundary occurs at $120^{\circ} \mathrm{E}$. For the Atlantic case, the Atlantic pattern was modified so that the edges of the box with the full anomalies were chosen as $88^{\circ}-13^{\circ} \mathrm{W}$, and $12^{\circ}-18^{\circ} \mathrm{N}$. The anomalies were tapered linearly north and south, with latitudes of $9^{\circ}$ and $21^{\circ} \mathrm{N}$ getting $1 / 2$ the anomaly, and with the anomaly going to 0 at latitudes of $6^{\circ}$ and $24^{\circ} \mathrm{N}$.

In addition to the patterns described above (based on annual mean SST), two other patterns were produced for the Pacific that attempt to separate the ENSO and longer-term patterns of variability. The long time scales were isolated by applying a filter to the monthly SST data that retains time scales of about $6 \mathrm{yr}$ and longer (Zhang et al. 1997). The high (residual) frequencies (shorter than 6 yr) were obtained by subtracting the lowfrequency filtered data from the unfiltered monthly data. The leading REOFs and associated PCs from both the low-pass (time scales of $6 \mathrm{yr}$ and longer) and residual (time scales shorter than $6 \mathrm{yr}$ ) data are shown in Fig. A1. In the case of the low-pass data we focus on the second REOF (the first is again the trend pattern shown in Fig. 1). The second low-frequency REOF shows the well-known, meridionally extensive pan-Pacific decadal pattern of variability (e.g., Barlow et al. 2001), with substantial middle-latitude amplitude that in the Northern Hemisphere is linked to the Pacific decadal oscillation (Zhang et al. 1997). In contrast, the leading REOF of the residual (high frequency) SST shows a clear ENSO structure with significant amplitudes that are largely confined to the central and eastern equatorial Pacific.

A final set of experiments was designed to assess the impact of soil moisture feedbacks. In this case either a standard multidecadal AMIP-style simulation or the control run was used to derive the climatological seasonal cycles of soil moisture content for each soil layer at each land point on the globe. Here the weekly resolution was preferred, but in cases where these were not available monthly data were used. Subsets of the above idealized SST simulations were then repeated in such a way 

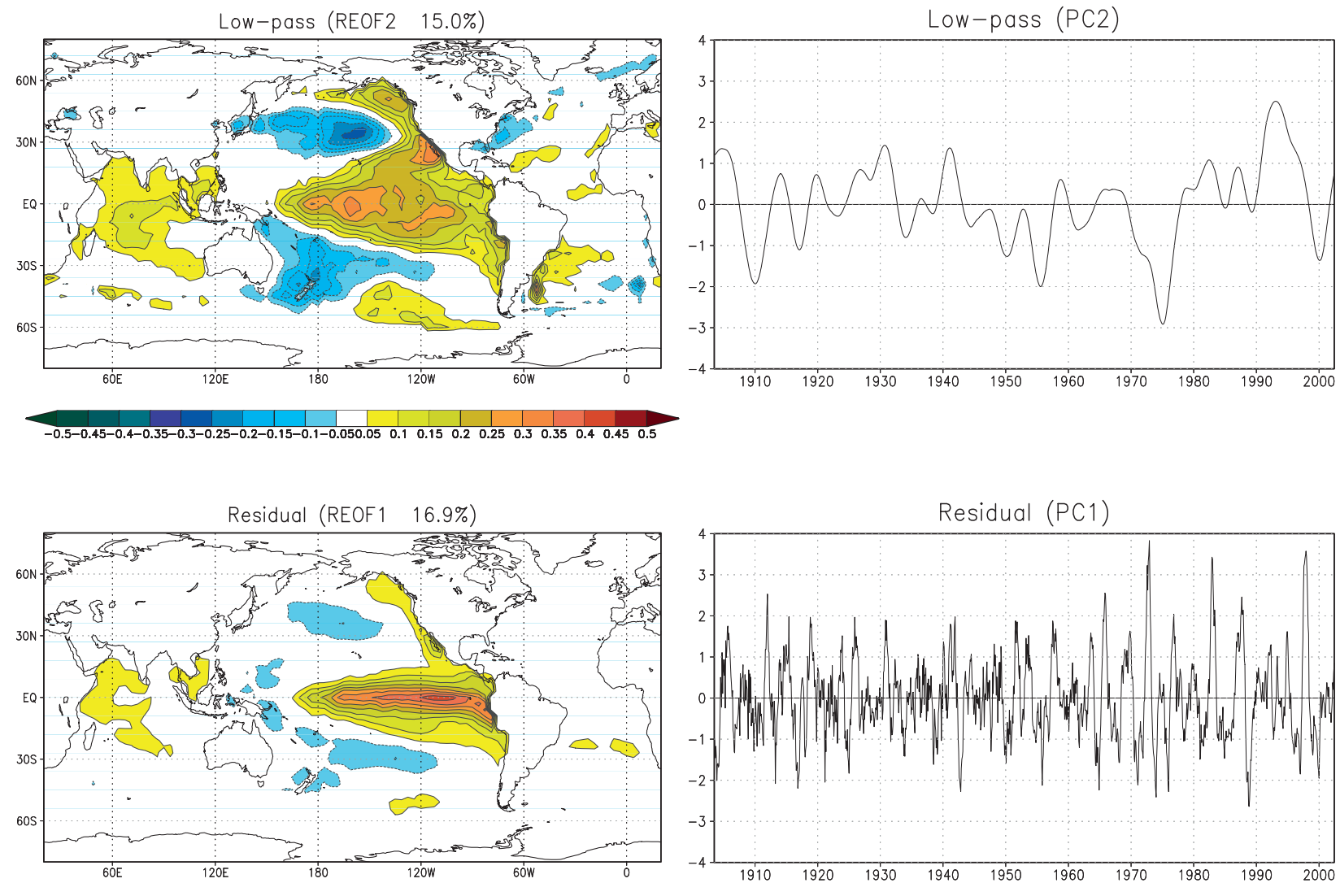

FIG. A1. (top) The second REOF and PC of the low-pass-filtered (time scales greater than 6 yr) monthly SST data. (bottom) The first REOF and PC of the high-pass-filtered (time scales less than 6 yr) monthly SST data. The results are based on the period of 1901-2004. The values are scaled so that the product of the REOF and $\mathrm{PC}$ gives units of ${ }^{\circ} \mathrm{C}$.

that at each time step, the simulated soil moisture states were thrown out and replaced with states that were interpolated from the climatological values established in the first simulation. Details of the various experiments and other information and links relevant to the U.S. CLIVAR drought working group project may be found online (available at http://gmao.gsfc.nasa.gov/research/ clivar_drought_wg/index.html).

\section{REFERENCES}

Adler, R. F., and Coauthors, 2003: The version 2 Global Precipitation Climatology Project (GPCP) Monthly Precipitation Analysis (1979-present). J. Hydrometeor., 4, 1147-1167.

An, S.-I., and J. Choi, 2008: Seasonal locking of the ENSO asymmetry and its influence on the seasonal cycle of the tropical eastern Pacific sea surface temperature. Atmos. Res., 94, 3-9, doi:10.1016/j.atmosres.2008.09.029.

Bacmeister, J., P. J. Pegion, S. D. Schubert, and M. J. Suarez, 2000: An Atlas of Seasonal Means Simulated by the NSIPP 1 Atmospheric GCM. NASA Tech. Memo. 104606, Vol. 17, Goddard Space Flight Center, 194 pp.
Barlow, M., S. Nigam, and E. H. Berbery, 2001: ENSO, Pacific decadal variability, and U.S. summertime precipitation, drought, and streamflow. J. Climate, 14, 2105-2128.

Bonan, G. B., 1996: The NCAR land surface model (LSM version 1.0) coupled to the NCAR community climate model. NCAR Tech. Rep. NCAR/TN-429 + STR, 171 pp.

Campana, K., and P. Caplan, Eds., 2005: Technical procedure bulletin for the T382 Global Forecast System. NOAA/NCEP/ EMC. [Available online at http://www.emc.ncep.noaa.gov/ gc_wmb/Documentation/TPBoct05/T382.TPB.FINAL.htm.]

Chen, J., A. D. Del Genio, B. E. Carlson, and M. G. Bosilovich, 2008: The spatiotemporal structure of twentieth-century climate variations in observations and reanalyses. Part I: Longterm trend. J. Climate, 21, 2611-2633.

Collins, W. D., and Coauthors, 2006: The Community Climate System Model version 3 (CCSM3). J. Climate, 19, 2122-2143.

Delworth, T. L., and Coauthors, 2006: GFDL's CM2 global coupled climate models. Part I: Formulation and simulation characteristics. J. Climate, 19, 643-674.

Ek, M., K. E. Mitchell, Y. Lin, E. Rogers, P. Grunmann, V. Koren, G. Gayno, and J. D. Tarpley, 2003: Implementation of Noah land surface model advances in the National Centers for Environmental Prediction operational mesoscale Eta model. J. Geophys. Res., 108, 8851, doi:10.1029/2002JD003296. 
Enfield, D., A. Mestas-Nuñez, and P. Trimble, 2001: The Atlantic Multidecadal Oscillation and its relation to rainfall and river flows in the continental U.S. Geophys. Res. Lett., 28, 2077-2080.

Gates, W. L., and Coauthors, 1999: An overview of the results of the Atmospheric Model Intercomparison Project (AMIP I). Bull. Amer. Meteor. Soc., 80, 29-55.

GFDL Global Atmospheric Model Development Team, 2004: The new GFDL Global Atmosphere and Land Model AM2-LM2: Evaluation with prescribed SST simulations. J. Climate, 17, 4641-4673.

Grell, G. A., 1993: Prognostic evaluation of assumptions used by cumulus parametrizations. Mon. Wea. Rev., 121, 764-787.

Gutzler, D. and S. Schubert, 2007: The U.S. CLIVAR Working Group on Long-Term Drought. CLIVAR Variations, Vol. 5, No. 1, International CLIVAR Project Office, Southampton, United Kingdom, 6-7.

Hack, J. J., 1994: Parameterization of moist convection in the National Center for Atmospheric Research Community Climate Model (CCM2). J. Geophys. Res., 99, 5551-5568.

Hoerling, M. P., and A. Kumar, 2003: The perfect ocean for drought. Science, 299, 691-699.

Kalnay, E., and Coauthors, 1996: The NCEP/NCAR 40-Year Reanalysis Project. Bull. Amer. Meteor. Soc., 77, 437-471.

Kiehl, J. T., J. J. Hack, G. Bonan, B. A. Boville, D. Williamson, and P. Rasch, 1998: The National Center for Atmospheric Research Community Climate Model: CCM3. J. Climate, 11, 1131-1149.

Koster, R. D., and M. J. Suarez, 1996: Energy and water balance calculations in the Mosaic LSM. NASA Tech. Memo. 104606, Vol. 9, 194 pp.

R. W. Higgins, and H. Van den Dool, 2003: Observational evidence that soil moisture variations affect precipitation. Geophys. Res. Lett., 30,1241, doi:10.1029/2002GL016571.

- and Coauthors, 2006: GLACE: The Global Land-Atmosphere Coupling Experiment. Part I: Overview. J. Hydrometeor., 7, 590-610.

McCabe, G. J., M. A. Palecki, and J. L. Betancourt, 2004: Pacific and Atlantic Ocean influences on multidecadal drought frequency in the United States. Proc. Natl. Acad. Sci. USA, 101, 4136-4141.

Milly, P. C. D., and A. B. Shmakin, 2002: Global modeling of land water and energy balances. Part I: The Land Dynamics (LaD) model. J. Hydrometeor., 3, 283-299.

Mo, K. C., J. N. Paegle, and R. W. Higgins, 1997: Atmospheric processes associated with summer floods and droughts in the central United States. J. Climate, 10, 3028-3046.

Moorthi, S., and M. J. Suarez, 1992: Relaxed Arakawa-Schubert: A parameterization of moist convection for general circulation models. Mon. Wea. Rev., 120, 978-1002.

Nigam, S., M. Barlow, and E. H. Berbery, 1999: Pacific decadal SST variability: Impact on U.S. drought and streamflow. Eos, Trans. Amer. Geophys. Union, 80, 621-625.

Oleson, K. W., and Coauthors, 2008: Improvements to the Community Land Model and their impact on the hydrological cycle. J. Geophys. Res., 113, G01021, doi:10.1029/2007JG000563.

Pan, H.-L., and W.-S. Wu, 1995: Implementing a mass flux convection parametrization for the NMC Office Note 409, 40 pp.
[Available from NOAA/NCEP/EMC, 5200 Auth Rd., Suitland, MD 20746.]

Rayner, N. A., D. E. Parker, E. B. Horton, C. K. Folland, L. V. Alexander, D. P. Rowell, E. C. Kent, and A. Kaplan, 2003: Global analyses of SST, sea ice, and night marine air temperature since the late nineteenth century. J. Geophys. Res., 108, 4407, doi:10.1029/2002JD002670.

Richman, M. B., 1986: Rotation of principal components. J. Climatol., 6, 293-335.

Ruiz-Barradas, A., and S. Nigam, 2004: Warm season rainfall variability over the U.S. Great Plains in observations, NCEP and ERA-40 reanalyses, and NCAR and NASA atmospheric model simulations. J. Climate, 18, 1808-1830.

Schubert, S. D., M. J. Suarez, P. J. Pegion, M. A. Kistler, and A. Kumer, 2002: Predictability of zonal means during boreal summer. J. Climate, 15, 420-434.

, R. D. Koster, and J. T. Bacmeister, 2004a: Causes of long-term drought in the U.S. Great Plains. J. Climate, 17, $485-503$.

$-,-\ldots,-$, and,$- 2004 \mathrm{~b}$ : On the cause of the 1930s Dust Bowl. Science, 303, 1855-1859, doi:10.1126/ science.1095048.

Seager, R., Y. Kushnir, C. Herweijer, N. Naik, and J. Velez, 2005: Modeling of tropical forcing of persistent droughts and pluvials over western North America: 1856-2000. J. Climate, 18, 4068-4091.

Stockli, R., and Coauthors, 2008: Use of FLUXNET in the Community Land Model development. J. Geophys. Res., 113, G01025, doi:10.1029/2007JG000562.

Ting, M., and H. Wang, 1997: Summertime U.S. precipitation variability and its relation to Pacific sea surface temperature. J. Climate, 10, 1853-1873.

Trenberth, K. E., and J. W. Hurrell, 1994: Decadal atmosphereocean variations in the Pacific. Climate Dyn., 9, 303-319.

— , and C. J. Guillemot, 1996: Physical processes involved in the 1988 drought and 1993 floods in North America. J. Climate, 9 , 1288-1298.

Vecchi, A. G., A. Clement, and B. J. Soden, 2008: Examining the tropical Pacific's response to global warming. Eos, Trans. Amer. Geophys. Union, 89, 81, doi:10.1029/2008EO090002.

Wang, C., D. B. Enfield, S.-K. Lee, and C. W. Landsea, 2006: Influences of the Atlantic warm pool on Western Hemisphere summer rainfall and Atlantic hurricanes. J. Climate, 19, 3011-3028.

- S.-K. Lee, and D. B. Enfield, 2008: Climate response to anomalously large and small Atlantic warm pools during the summer. J. Climate, 21, 2437-2450.

Wang, H., S. Schubert, M. Suarez, J. Chen, M. Hoerling, A. Kumar, and P. Pegion, 2009: Attribution of the seasonality and regionality in climate trends over the United States during 1950-2000. J. Climate, 22, 2571-2590.

Zhang, G. J., and N. A. McFarlane, 1995: Sensitivity of climate simulations to the parameterization of cumulus convection in the Canadian Climate Centre general circulation model. Atmos.-Ocean, 33, 407-446.

Zhang, Y., J. M. Wallace, and D. S. Battisti, 1997: ENSO-like interdecadal variability. J. Climate, 10, 1004-1020. 